\title{
The influence of aerosol particle number and hygroscopicity on the evolution of convective cloud systems and their precipitation: A numerical study based on the COPS observations on 12 August 2007
}

\author{
Céline Planche $^{\mathrm{a}, \mathrm{b}}$, Wolfram Wobrock ${ }^{\mathrm{a}, \mathrm{b}}$, Andrea I. Flossmann ${ }^{\mathrm{a}, \mathrm{b}, *}$, Frédéric Tridon ${ }^{\mathrm{a}, \mathrm{b}}$, \\ Joël Van Baelen ${ }^{\mathrm{a}, \mathrm{b}}$, Yves Pointin ${ }^{\mathrm{a}, \mathrm{b}}$, Martin Hagen ${ }^{\mathrm{c}}$ \\ a Clermont Université, Université Blaise Pascal, Laboratoire de Météorologie Physique, F-63000 Clermont-Ferrand, France \\ b CNRS, INSU, UMR 6016, LaMP, F-63177 Aubière, France \\ c Deutsches Zentrum für Luft- und Raumfahrt (DLR), Oberpfaffenhofen, Germany
}

\section{A R T I C L E I N F O}

\section{Article history:}

Received 28 September 2009

Received in revised form 11 May 2010

Accepted 18 May 2010

\section{Keywords:}

Cloud modelling

Bin resolved microphysics

Sensitivity to aerosol particles COPS

\begin{abstract}
A B S T R A C T
The 3D cloud model DESCAM-3D with bin resolved microphysics for ice, water and aerosol particles is used to study the role of particles on the evolution of summertime mid-level convective clouds and the subsequent precipitation during the COPS field campaign which occurred at mid-latitude near the French/German border in summer 2007.

Using a 3D grid resolution of $250 \mathrm{~m}$, DESCAM-3D, is able to simulate well the dynamical, cloud and precipitation features of the convective cloud system observed during the afternoon of the 12th August. This mid-level convective system was dominated by warm-phase microphysics. The simulated convective system led to a $1.5 \mathrm{~h}$ long lasting precipitation event in agreement with the radar observations. The results of the fine numerical scale compare well with the high resolved radar reflectivities of the LaMP X-band radar and the DLR-Poldirad radar. The prediction of the liquid hydrometeor spectra allows a detailed calculation of the cloud radar reflectivity.

In order to better understand the role of aerosol particles on cloud evolution and precipitation formation, several sensitivity studies were performed by modifying aerosol number concentration as well as their physico-chemical properties. Drastic changes in the aerosol solubility lead to a variation in precipitation on the order of $10 \%$ for the same convective case. In contrast, changes in the aerosol number concentrations can lead to a variation in total precipitation of up to $30 \%$. Hence, the role of changes in aerosol number concentrations is more important than changes in particle solubility for this case of continental mid-level convection at mid-latitude.

A subsequent analysis of the in-cloud microphysics revealed that in-cloud properties are modified significantly in all scenarios. Key parameter is the supersaturation whose magnitude influences both cloud microphysics (cloud droplet and rain drop formation) as well as cloud thermodynamics and cloud dynamics. Furthermore, supersaturation can remain quite low in polluted clouds reducing strongly the release of latent heat and, thus, the intensity of the convective dynamics. As much as a quarter of the polluted cloud volume was found to be subsaturated in this case whereas it was smaller in the continental or clean environments.
\end{abstract}

(C) 2010 Elsevier B.V. All rights reserved.
* Corresponding author. LaMP/OPGC, Université Blaise Pascal, 24 avenue des Landais, 63177 Aubière, France.

E-mail address: A.Flossmann@opgc.univ-bpclermont.fr (A.I. Flossmann).

\section{Introduction}

In the general debate about climate change, the impact of air pollution on clouds, in particular the aerosol indirect effect (Twomey, 1974; Albrecht, 1989), is in the centre of numerous 
studies. Indeed, the cloud feedbacks remain the largest source of uncertainty in climate sensitivity estimates (Solomon et al., 2007). Thus, many studies have tried to understand the role of aerosol particles in the formation and evolution of clouds (see, e.g., Levin and Cotton, 2009) and the possible consequences of anthropogenic changes in these particle populations. Here, especially numerical models treating cloud microphysics in a bin resolved way can provide important insight, as cloud droplet nucleation is governed by supersaturation, a parameter which is not followed explicitly by common meso-scale models.

In the past, efforts have been made to study the impact of changing aerosol particle population on the evolution and precipitation of clouds in 2-D (e.g. Connolly et al., 2006; Yin et al., 2005; Teller and Levin, 2006) or 3-D (e.g. Yi et al., 2008; Leroy et al., 2009) meso-scale models. However, due to the costs of such detailed simulations, the domains considered were generally small and contained just one isolated cloud. The above cited studies reported a reduction of precipitation in a more polluted environment, while other publications (e.g. Lee et al., 2008) point out that an increase of aerosol number concentration can also result in an increase of precipitation, depending on the case studied.

Due to the computational burden of 3D bin microphysics simulations previous studies have either considered an isolated cloud only and/or used a simplified bulk microphysics approach. This paper presents a first attempt to simulate in a 3D bin manner the aerosol/cloud interaction for an entire cloud field as observed during COPS (Convective and Orographically-induced Precipitation Study; Wulfmeyer et al., 2008) at mid-latitudes near the French/German border in summer 2007. After a comparison with observations, the role of the aerosol number concentration and composition is studied in detail.

The main model features are summarized in Section 2. A brief description of the studied mid-latitude mid-level convective cloud system of COPS and the comparison between the modelled results and the available observation data are presented in Section 3. Section 4 shows sensitivity studies about the role of the aerosol particle spectrum and solubility. The consequences of the initial aerosol particle concentration and solubility for the "in-cloud microphysics" are detailed in Section 5, and Section 6 summarizes and concludes the findings.

\section{Model description}

The 3D model with detailed (bin) microphysics used herein couples the 3D non-hydrostatic model of Clark and Hall (1991) with the Detailed Scavenging Model DESCAM (Flossmann and Pruppacher, 1988; Leroy et al., 2007, 2009; Flossmann and Wobrock, 2010) for the microphysical package.

The microphysical scheme simulates the number distribution functions for the aerosol particles $f_{\mathrm{AP}}\left(m_{\mathrm{AP}}\right)$ and for drops $f_{\mathrm{d}}(m)$. Both number distributions use a logarithmically equidistant spaced mass coordinates $m_{\mathrm{AP}}$ for wetted aerosol particles and $m$ for drops both with mass doubling for 2 subsequent bins. $g_{\mathrm{AP}, \mathrm{d}}(m)$ is the mass density distribution of aerosol material in cloud and rain drops. All functions are discretized in 39 bins covering the range from $1 \mathrm{~nm}$ to $7 \mu \mathrm{m}$ for wet aerosol particles and $1 \mu \mathrm{m}$ to $12 \mathrm{~mm}$ for drops. With both functions $f_{\mathrm{d}}(m)$ and $g_{\mathrm{AP}, \mathrm{d}}(m)$, the mean mass $\overline{\mathrm{m}}_{\mathrm{AP}}(m)$ of the aerosol particle inside a drop bin of mass $m$ can be calculated using the following relation (the different symbols are explained in the Appendix A):

$\bar{m}_{\mathrm{AP}}(m)=\frac{g_{\mathrm{AP}, \mathrm{d}}(m)}{f_{\mathrm{d}}(m)}$

Due to this additional information, the drop growth rate can be calculated taking into account the aerosol composition.

The following equations summarize the evolution of distribution functions of wet aerosol particles number, droplet number and aerosol mass in the drops:

$$
\begin{aligned}
\frac{\partial f_{\mathrm{AP}}\left(m_{\mathrm{AP}}\right)}{\partial t}= & \underbrace{\left.\frac{\partial f_{\mathrm{AP}}}{\partial t}\right|_{\text {dyn }}}_{\text {termI }}+\underbrace{\left.\frac{\partial f_{\mathrm{AP}}}{\partial t}\right|_{\text {act } / \text { desact }}}_{\text {termII }}+\underbrace{\left.\frac{\partial f_{\mathrm{AP}}}{\partial t}\right|_{\text {nucl,ice }}}_{\text {termIII }} \\
& +\underbrace{\left.\frac{\partial f_{\mathrm{AP}}}{\partial t}\right|_{\text {cond/eva }}}_{\text {termIV }}
\end{aligned}
$$

$$
\begin{aligned}
\frac{\partial f_{\mathrm{d}}(m)}{\partial t}= & \underbrace{\left.\frac{\partial f_{\mathrm{d}}}{\partial t}\right|_{\text {dyn }}}_{\text {termV }}+\underbrace{\left.\frac{\partial f_{\mathrm{d}}}{\partial t}\right|_{\text {act/desact }}}_{\text {termVI }}+\underbrace{\left.\frac{\partial f_{\mathrm{d}}}{\partial t}\right|_{\text {cond/eva }}}_{\text {termVII }} \\
& +\underbrace{\left.\frac{\partial f_{\mathrm{d}}}{\partial t}\right|_{\text {coal }}}_{\text {termVIII }}+\underbrace{\left.\frac{\partial f_{\mathrm{d}}}{\partial t}\right|_{\text {nucl,ice }}}_{\text {termIX }}+\underbrace{\left.\frac{\partial f_{\mathrm{d}}}{\partial t}\right|_{\text {rim }}}_{\text {termX }}+\underbrace{\left.\frac{\partial f_{\mathrm{d}}}{\partial t}\right|_{\text {melt }}}_{\text {termXI }}
\end{aligned}
$$

$$
\begin{aligned}
\frac{\partial g_{\mathrm{AP}, \mathrm{d}}(m)}{\partial t}= & \underbrace{\left.\frac{\partial g_{\mathrm{AP}, \mathrm{d}}}{\partial t}\right|_{\text {dyn }}}_{\text {termV }}+\underbrace{\left.\frac{\partial g_{\mathrm{AP}, \mathrm{d}}}{\partial t}\right|_{\text {act } / \text { desact }}}_{\text {termVI }}+\underbrace{\left.\frac{\partial g_{\mathrm{AP}, \mathrm{d}}}{\partial t}\right|_{\text {cond/eva }}}_{\text {termVII }} \\
& +\underbrace{\left.\frac{\partial g_{\mathrm{AP}, \mathrm{d}}}{\partial t}\right|_{\text {coal }}}_{\text {termVIII }}+\underbrace{\left.\frac{\partial g_{\mathrm{AP}, \mathrm{d}}}{\partial t}\right|_{\text {nucl,ice }}}_{\text {termIX }}+\underbrace{\left.\frac{\partial g_{\mathrm{AP}, \mathrm{d}}}{\partial t}\right|_{\text {rim }}}_{\text {termX }} \\
& +\underbrace{\left.\frac{\partial g_{\mathrm{AP}, \mathrm{d}}}{\partial t}\right|_{\text {melt }}}_{\text {termXI }}
\end{aligned}
$$

Term I and V represent the changes due to the dynamics (transport). The collision and coalescence process of drops is represented by the term VIII.

Both aerosol particles and droplets can be nucleated to form ice crystals (terms III and IX). The drop distribution function is also affected by the riming process (term X). The growth of drops by vapour diffusion (term VII) is treated using the formulas for the growth rate from Pruppacher and Klett (1997). Coalescence and riming are treated with the numerical scheme of Bott (1998). The collection kernels for coalescence of drops are calculated with the collection efficiencies of Hall (1980) and the terminal velocities of Pruppacher and Klett (1997). 
Aerosol particles are supposed to be in equilibrium with environmental water vapour following Köhler theory:

$\ln (S+1)=\frac{A}{r}-\frac{B r_{N}^{3}}{r^{3}-r_{N}^{3}}$

with $A=\frac{2 \sigma_{w, a} M_{w}}{\Re T \rho_{w}}$ and $B=\frac{\nu \varepsilon \Phi_{s} M_{w} \rho_{N}}{M_{s} \rho_{w}}$.

At each time step, the new aerosol particle equilibrium size is calculated following the ambient humidity variations, however imposing that aerosol particle growth does not exceed the equilibrium value of $100 \%$ relative humidity. In order to calculate the critical radius for activation $r_{\text {act }}\left(r_{N}\right)$ we use the procedure described in detail in Leroy et al. (2007). The value $r_{N}^{3}$ corresponds to the dry aerosol nucleus mass which can be calculated from the above Köhler equation as $r^{3}$ is given by the wet aerosol mass grid $m_{\mathrm{AP}}$. The activation radius is used as the threshold between non-activated and activated particles that are going to be transferred into the droplet reservoir (terms II and VI). The detailed procedure is described in Leroy et al. (2007).

Also, during the dissipation stage of the cloud, when cloudy air becomes subsaturated, drops with radius smaller than $r_{\text {act }}\left(\overline{r_{N}}\right)$ are deactivated and thus transferred into the wet aerosol particle reservoir. The radius of the resulting wet aerosol particles is again calculated by solving the Köhler equation with the knowledge of the supersaturation $S$ and the mean dry radius $\overline{r_{N}}$ given by $\overline{\mathrm{m}}_{\mathrm{AP}}$. This microphysical scheme was already successfully tested against a more sophisticated microphysical model (Leroy et al., 2007).

The ice phase is represented in a similar way with two distribution functions $f_{i}\left(m_{i}\right)$ and $g_{\mathrm{AP}, i}\left(m_{i}\right)$. Ice crystals are assumed to be spherical and the density of ice is set to $0.9 \mathrm{~g} \mathrm{~m}^{-3}$.

$$
\begin{aligned}
& \frac{\partial f_{i}\left(m_{i}\right)}{\partial t}=\left.\frac{\partial f_{\mathrm{i}}}{\partial t}\right|_{\text {dyn }}+\left.\frac{\partial f_{\mathrm{i}}}{\partial t}\right|_{\text {nucl,ice }}+\left.\frac{\partial f_{\mathrm{i}}}{\partial t}\right|_{\text {dep/sub }}+\left.\frac{\partial f_{\mathrm{i}}}{\partial t}\right|_{\text {rim }}+\left.\frac{\partial f_{\mathrm{i}}}{\partial t}\right|_{\text {melt }}
\end{aligned}
$$

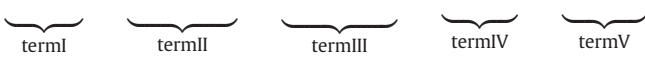

$$
\begin{aligned}
& \frac{\partial g_{\mathrm{AP}, \mathrm{i}}\left(m_{i}\right)}{\partial t}=\underbrace{\left.\frac{\partial g_{\mathrm{AP}, \mathrm{i}}}{\partial t}\right|_{\text {dyn }}}_{\text {termI }}+\underbrace{\left.\frac{\partial g_{\mathrm{AP}, \mathrm{i}}}{\partial t}\right|_{\text {nucl,ice }}}_{\text {termII }}+\underbrace{\left.\frac{\partial g_{\mathrm{AP}, \mathrm{i}}}{\partial t}\right|_{\text {dep } / \text { sub }}}_{\text {termIII }} \\
& +\left.\frac{\partial g_{\mathrm{AP}, \mathrm{i}}}{\partial t}\right|_{\text {rim }}+\left.\frac{\partial g_{\mathrm{AP}, \mathrm{i}}}{\partial t}\right|_{\text {melt }} \\
& \underbrace{}_{\text {termIV }} \underbrace{\text { dr }}_{\text {termV }}
\end{aligned}
$$

Ice crystals are produced by homogeneous and heterogeneous nucleation (term II) and then grow by vapour deposition (term III) and riming (term IV). Growth rate of ice crystals are given by Pruppacher and Klett (1997). Heterogeneous nucleation is described according to Meyers et al. (1992). Their formula gives the number of ice crystals $\left(N_{\mathrm{IN}}\right)$ as a function of supersaturation with respect to ice $\left(s_{v, i}\right)$. Homogeneous nucleation follows the parameterization of Koop et al. (2000).

The riming description includes collection of droplets by large ice crystals as well as accretion by the collection of small ice particles by large drops. The collection kernels for riming are set to be the same as those for coalescence of drops. We assume that the collection efficiency of a spherical ice particle is equal to that of a water drop of the same mass. The terminal velocities of the ice crystals are calculated following Heymsfield and Iaquinta (2000).

Ice particles are assumed to melt (term V and term XI for the drop distribution functions) instantaneously and completely when they reach the $0{ }^{\circ} \mathrm{C}$ level. Consequently, we neglect aggregation which is most efficient around $0{ }^{\circ} \mathrm{C}$ when the ice particles develop a pseudo-liquid layer (Pruppacher and Klett, 1997). Furthermore, the model is not yet treating secondary production of ice particles during riming. Thus, the representation of the ice phase certainly merits improvement for the simulation of clouds which develop significantly in supercooled regions.

However, for the studies presented here we will be interested in a convective cloud system of medium height where the liquid phase dominates, and impact of the ice phase is marginal as will be shown also below.

\section{Simulation of the convective cloud system of 12th August 2007}

\subsection{COPS observations on 12th Aug. 2007}

COPS (Convective and Orographically-induced Precipitation formation Study) was an international field campaign taking place at the French/German border (in the Upper Rhine Valley, the Black Forest and the Vosges Mountains, see Fig. 1) during summer 2007.

The aim of COPS was to study the orographic influence on precipitation and to improve cloud representation in forecast models (Wulfmeyer et al., 2008).

The LaMP X-band radar was deployed for 3 months within the Vosges French supersite Bischenberg, at Obernai near Strasbourg (Fig. 2). It is designed to provide the precipitation field over a typical domain of a small catchment basin (about $20 \mathrm{~km}$ range) using a beam elevation of $5^{\circ}$. The major characteristic of the system is its high spatial and temporal resolution (60 $\mathrm{m}$ in range, $2^{\circ}$ in azimuth and $30 \mathrm{~s}$ in time)

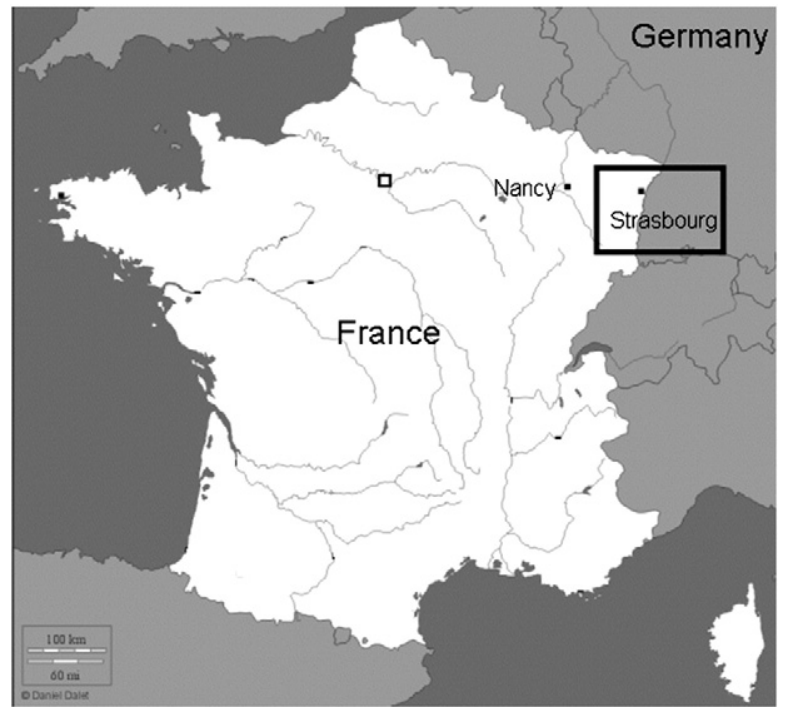

Fig. 1. Location of the COPS experiment. 


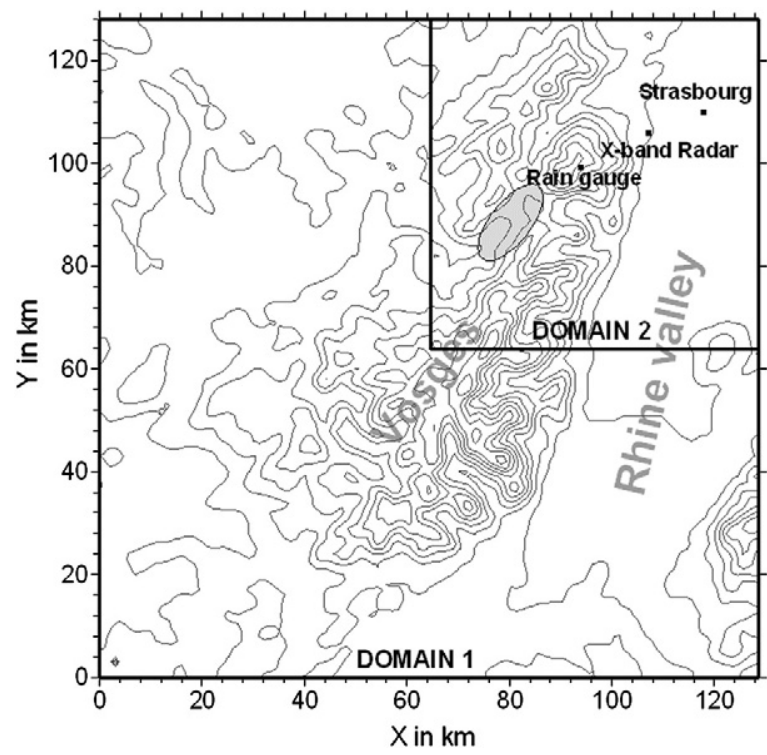

Fig. 2. Representation of the different model domains. The elliptic surface indicates the Bruche and Fave valley where the surface heating was enhanced.

(Van Baelen et al., 2009). Its observational area was also covered by the DLR polarimetric C-band Doppler radar POLDIRAD (Schroth et al., 1988) deployed $20 \mathrm{~km}$ north- west of Strasbourg. During COPS, POLDIRAD followed a dedicated observation strategy of which we are using the $2^{\circ}$ elevation reflectivity scans with a resolution of $300 \mathrm{~m}$ and a range of $120 \mathrm{~km}$ repeated every $10 \mathrm{~min}$.

Fig. 3 shows the large scale meteorological conditions for the study case which was a typical summertime convection in a situation with weak gradients. Indeed, a weak front associated to a low pressure system over Scotland approached the COPS area. The wind speed was low at the surface and was oriented south-westerly. Above $700 \mathrm{hPa}$ the wind speed increased and turned more southerly. At the surface the air was hot with cold air above and downwind of the front some thunderstorms appeared in Western Europe due to convection which was triggered thermally over the mountains.

The thermodynamic and dynamic conditions are given by the sounding of Nancy (France), 12 UTC (see Figs. 1 and 4).

At the beginning of the afternoon, a precipitating cloud cluster was observed with the X-band and the POLDIRAD radars (right columns of the Figs. 6 and 7). It formed over the Vosges Mountains and stayed almost at the same place for about $1 \mathrm{~h}$. Observations on the cloud height are not available. The following modelling results indicate a cloud top height of 4 to $5 \mathrm{~km}$. As the freezing level (Fig. 4) was located at around $3.3 \mathrm{~km}$, the presence of the ice phase in the first $4 \mathrm{~km}$ is almost negligible. The simulated ice water content above $4 \mathrm{~km}$ showed values below $0.0002 \mathrm{~g} / \mathrm{m}^{3}$. The horizontal polarimetric scans of

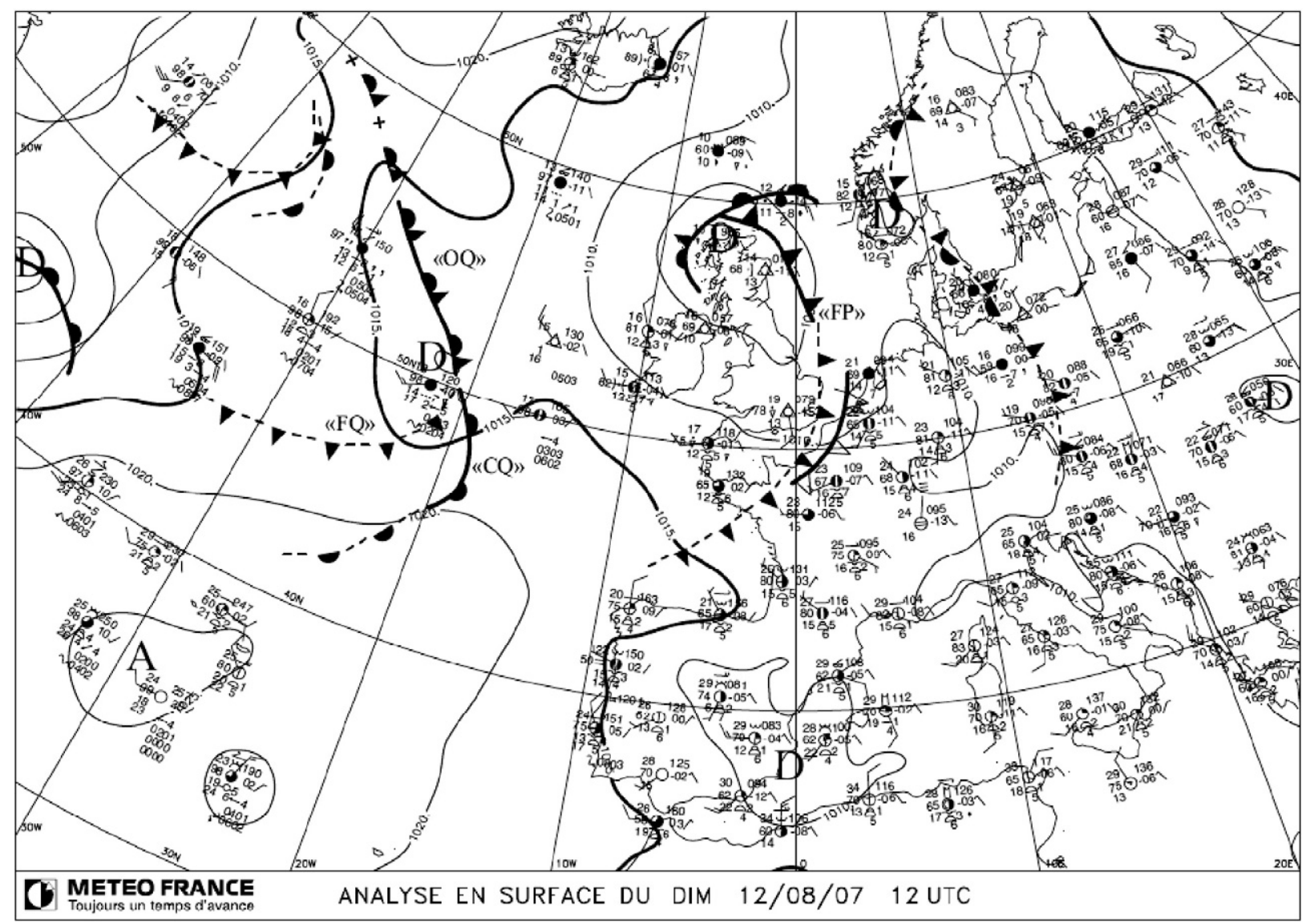

Fig. 3. Surface analysis of the meteorological conditions of the 12 August 2007 at 12 h UTC. 


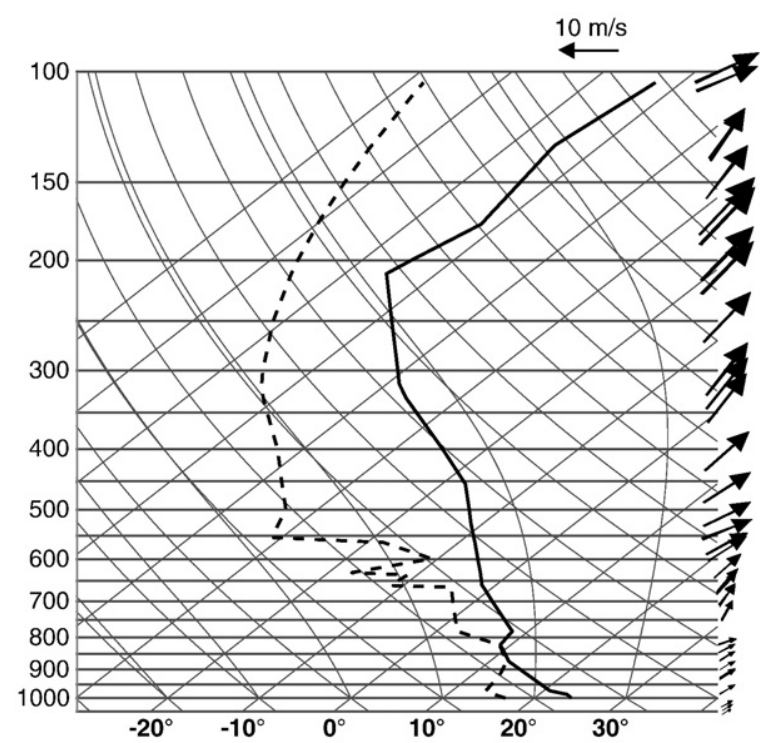

Fig. 4. Temperature (solid line) and dew point temperature (dashed line) profiles from the sounding at Nancy, 12 August 2007, 12 UTC.

Poldirad in altitudes between 0.8 to $2.0 \mathrm{~km}$ did not give any indications of ice in the precipitation field. Thus, in the further discussion of the paper, we will disregard the role of the ice phase and consequently, the aerosol effects on precipitation studied hereafter will represent mid-level convective clouds dominated by warm-phase microphysics.

\subsection{Model setup}

The model domain is set to $130 \mathrm{~km} \times 130 \mathrm{~km}$ in the horizontal and $16 \mathrm{~km}$ in the vertical. The resolution is $1 \mathrm{~km}$ for the horizontal coordinates and $200 \mathrm{~m}$ for the vertical one. A second domain with a surface $64 \times 64 \mathrm{~km}^{2}$ and grid resolution of $250 \mathrm{~m}$ is nested into the area of interest. The model domains are represented in Fig. 2.

Moreover, to initialize convection, sensible and latent surface heat fluxes with mean values of $30 \mathrm{~W} / \mathrm{m}^{2}$ and $100 \mathrm{~W} / \mathrm{m}^{2}$ respectively were imposed over the entire terrain. In order to trigger the convection we increased the heat flux in the Bruche and Fave valley upwind of the observed convective system as indicated by the elliptic surface in Fig. 2. The fluxes were increased to $70 \mathrm{~W} / \mathrm{m}^{2}$ for sensible heat and to $250 \mathrm{~W} / \mathrm{m}^{2}$ for latent heat. These quantities correspond well to the maximum values which were typically observed at noon time during COPS experiment (Eigenmann et al., 2009).

The initial aerosol particles distribution follows Jaenicke (1988) for a continental air mass, which corresponds to the solid line in Fig. 5. The total number of aerosol particles in the boundary layer is $1411 \mathrm{~cm}^{-3}$ and the particles are assumed to be ammonium sulphate, entirely soluble and with a molecular weight of $132 \mathrm{~g} \mathrm{~mol}^{-1}$. The aerosol particle concentration decreased exponentially up to $3 \mathrm{~km}$, above it is kept constant. Further on (Section 4), this simulated case will be referred to as "reference case".

The boundary conditions of the model assume free-slip conditions for the momentum components and zero normal second derivatives of all scalar variables at the upper and lower surface of the model. In order to prevent reflection of the vertically propagating gravity waves at the model top, a Rayleigh friction and Newtonian cooling absorber are employed in the uppermost region of the model. The lateral boundary conditions are approximated by an open boundary extrapolation scheme. Various aspects of the model boundary conditions and the nesting techniques were discussed in Clark (1977, 1982) and Clark and Farley (1984). The dynamical time step for the simulations is $3 \mathrm{~s}$. Condensational growth needs significantly smaller time steps. The procedure can be found in Leroy (2007).

\subsection{Results of the simulation of the COPS case}

We now compare the simulation results with the available observation data. In a first step, we concentrate on the radar observations. Fig. 6 shows the radar reflectivity field observed by the X-band radar and the modelling results of DESCAM 3D at different times that correspond to the beginning of the precipitation, and to $20 \mathrm{~min}$ and to $60 \mathrm{~min}$ after precipitation onset. To facilitate the comparison between model and radar observation, simulation results are presented for the same Plan Position Indicator (PPI) as the X-band observations (i.e. an elevation of $5^{\circ}$ ). The model results outside the observation area of the $\mathrm{X}$-band radar are not represented. We also used the data of the POLDIRAD radar, situated at $30 \mathrm{~km}$ to the north of the X-band position and $20 \mathrm{~km}$ to the north-west of Strasbourg, whose range is significantly larger than the one of the X-band. Fig. 7 compares the radar reflectivity field observed by the POLDIRAD radar for $2^{\circ}$ elevation with the model results in the corresponding PPI cross sections.

The cloud system forms in the south-west of the observed area and moves to the centre while the radar reflectivity intensity decreases. The clouds disappear over the Rhine valley about $1.5 \mathrm{~h}$ after they were formed. The observed altitudes in the radar plots are different due to different zenith scanning angles of the two radars. For example, if we compare the radar observation data at 14 h UTC (see Figs. 6c

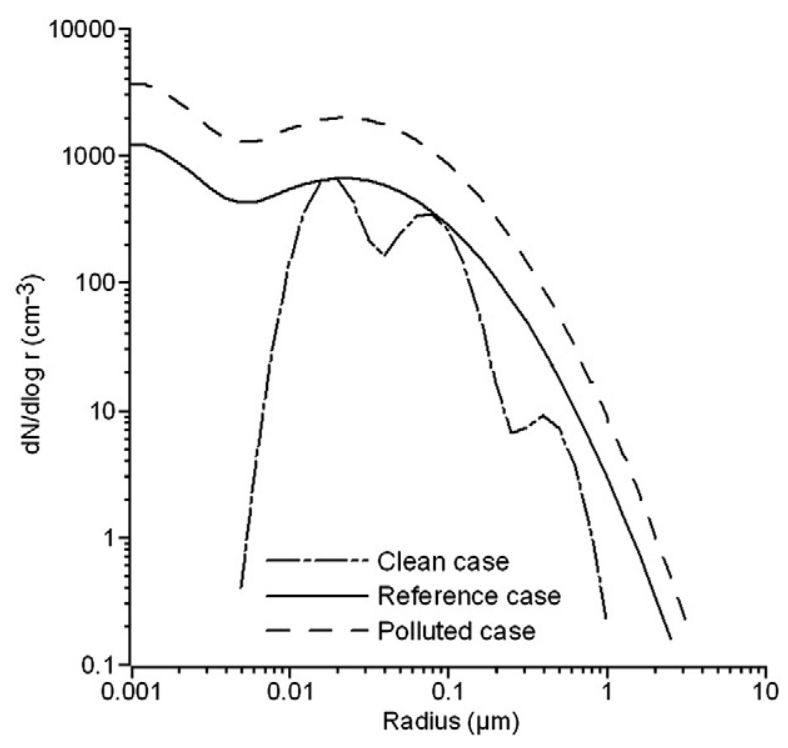

Fig. 5. Initial aerosol particle spectra for the reference, clean and polluted cases. 
a)

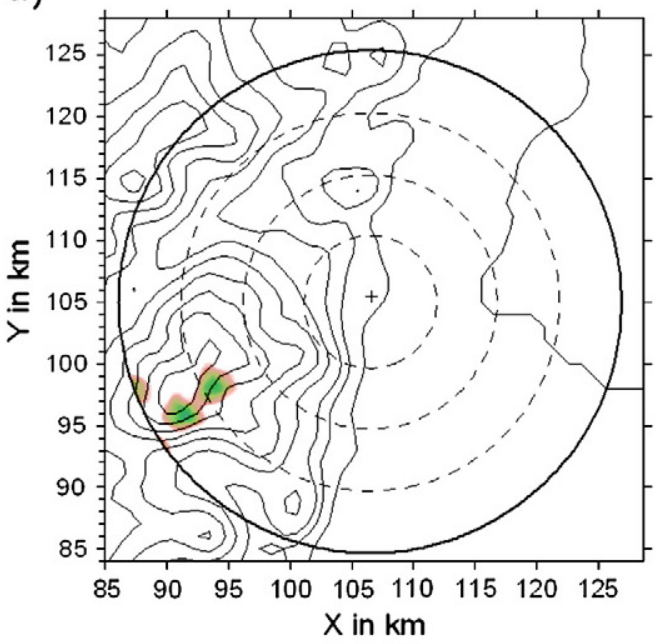

b)

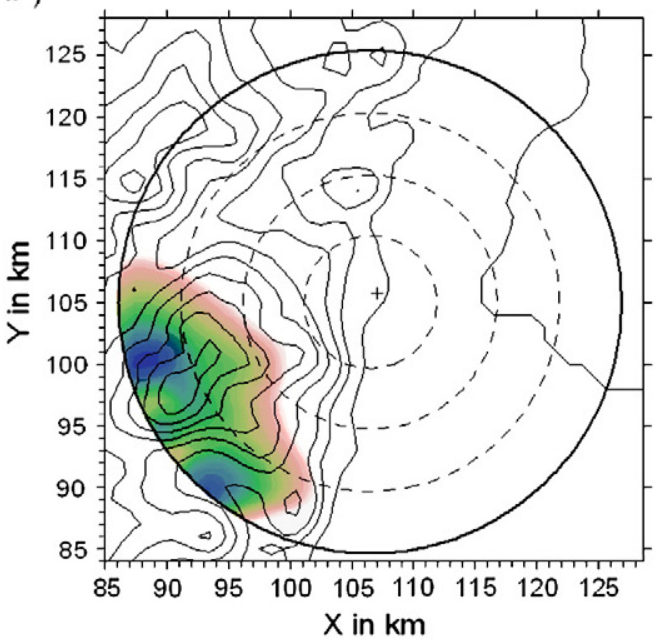

c)

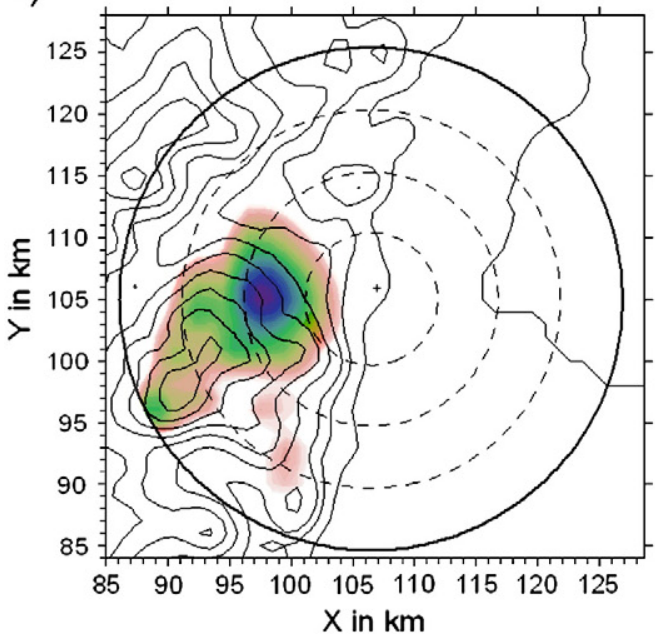

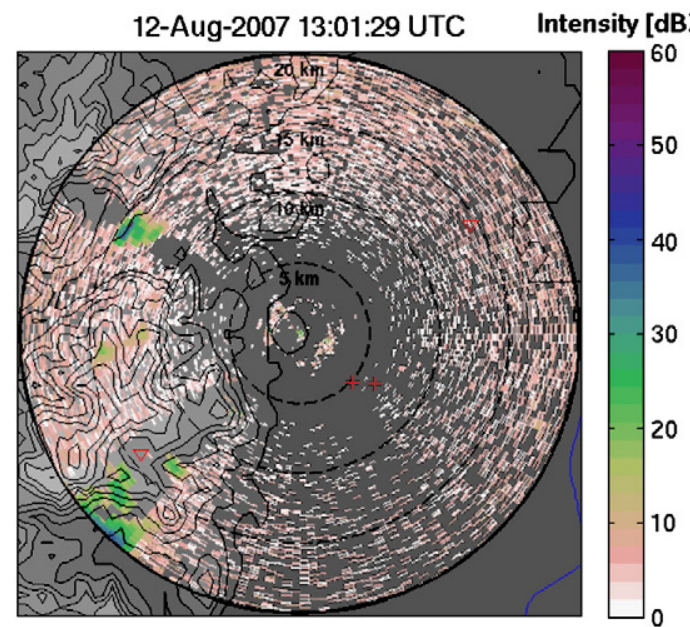

12-Aug-2007 13:22:00 UTC Intensity [dBZ]

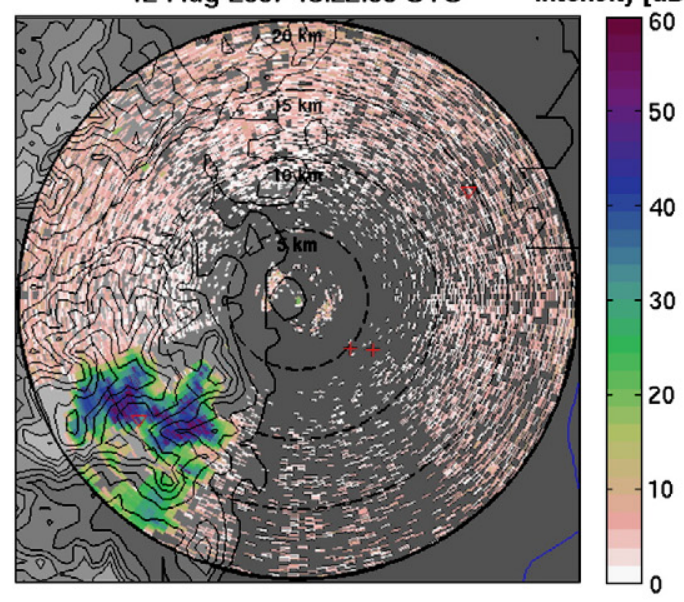

40

30

20

10

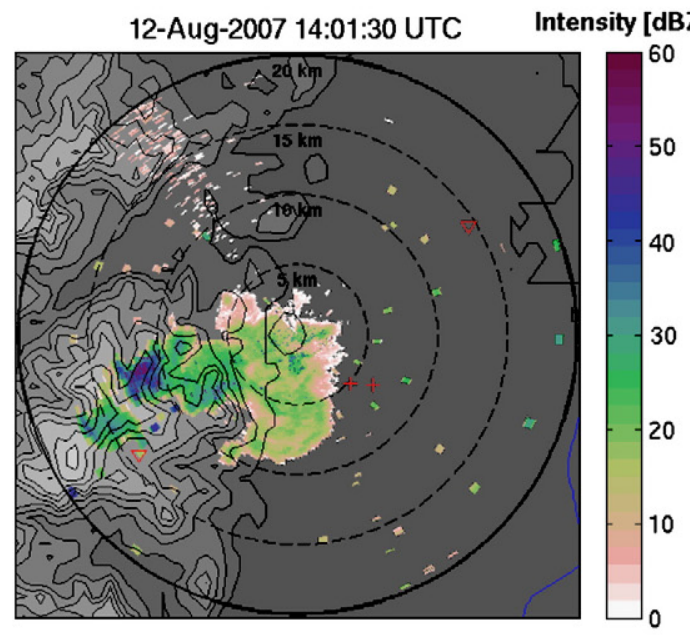

Fig. 6. Comparison between the radar reflectivity modelled with DESCAM (left) and observed (right) with the LaMP X-band radar at different time steps. The times a, b and c represent the radar reflectivity field at the beginning of the precipitation, 20 min and 60 min after precipitation starts, respectively. The representation of these figures is the Plan Position Indicator (PPI) Radar Image. The model results outside the observation area are not represented. 
a)

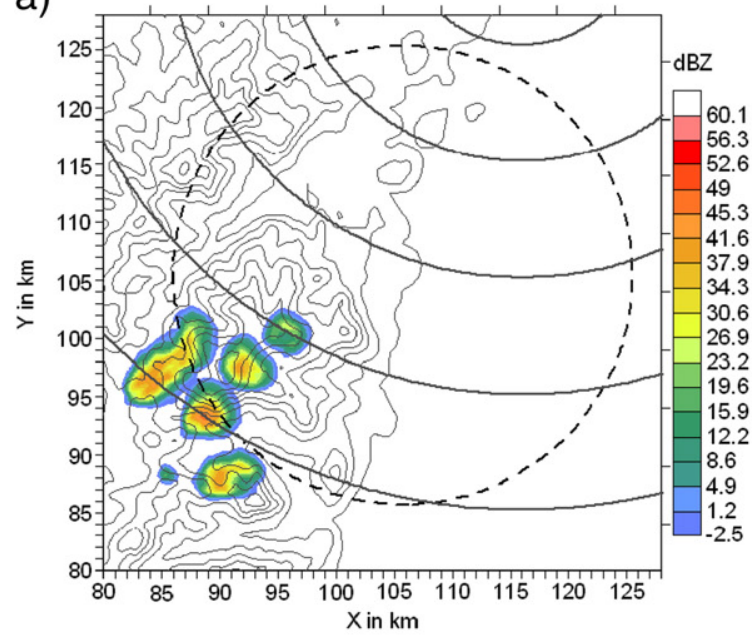

b)

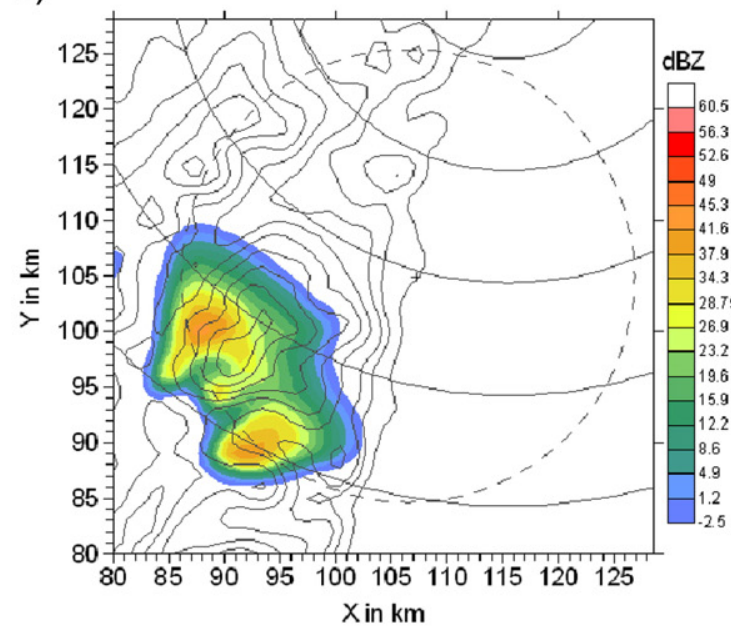

c)

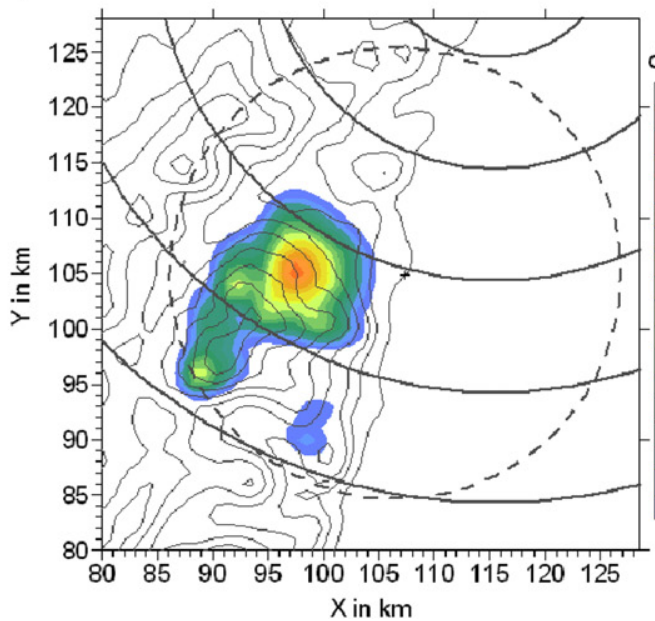

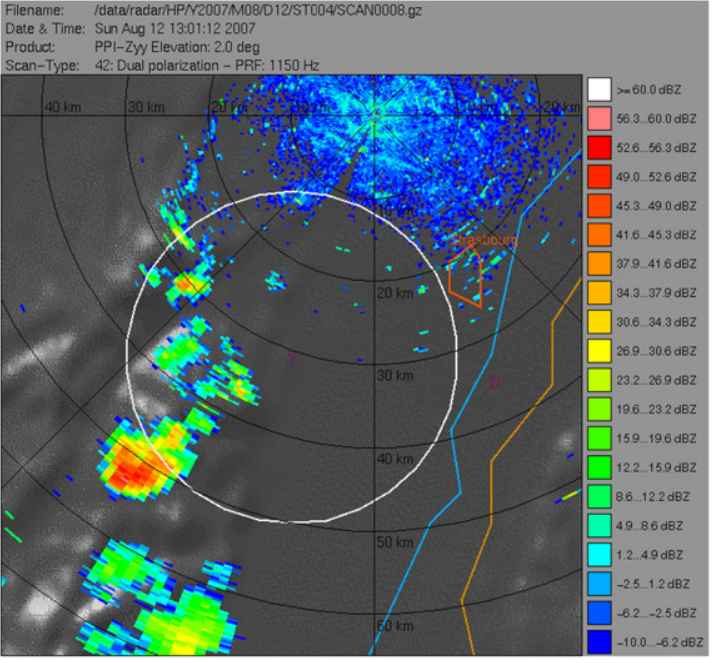
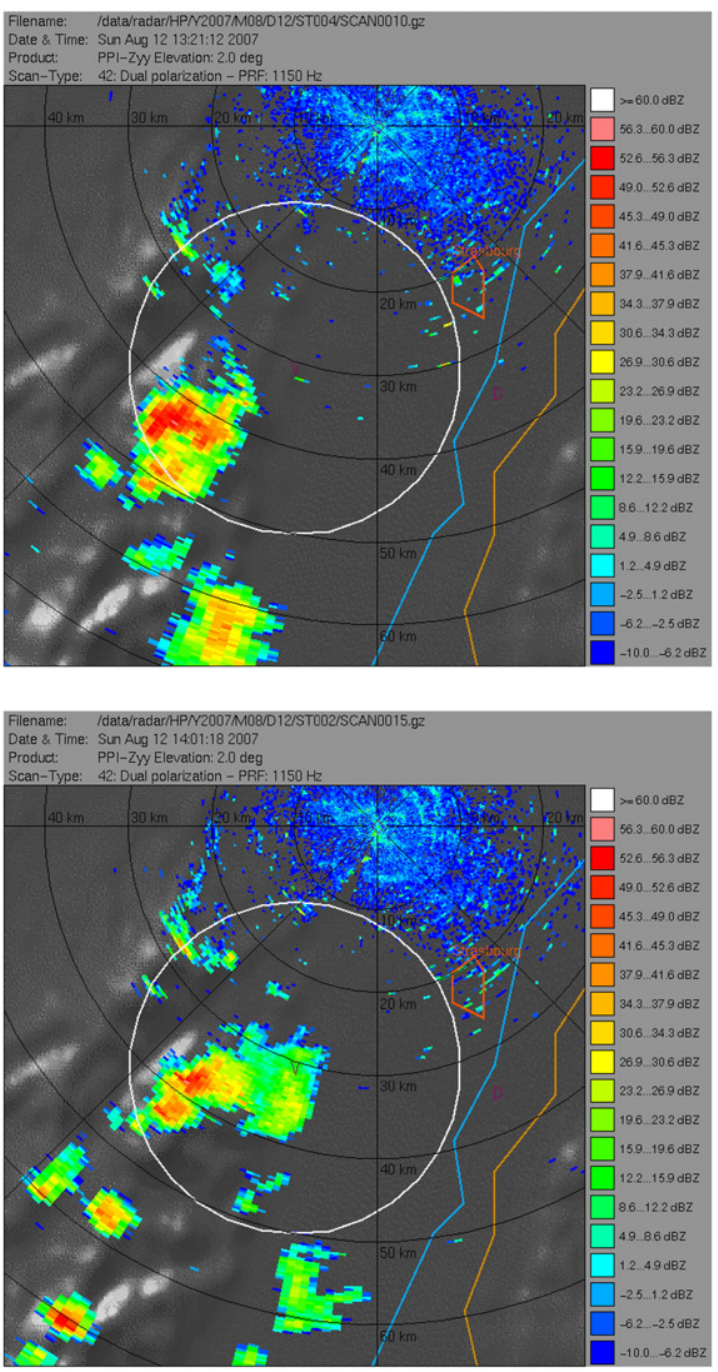

Fig. 7. Comparison between the radar reflectivity modelled with DESCAM (left) and observed (right) with the Poldirad radar at different time steps. The times a, b and $\mathrm{c}$ represent the radar reflectivity field at the beginning of the precipitation, 20 min and 60 min after precipitation starts, respectively. The representation of these figures is the Plan Position Indicator (PPI) Radar Image. The continuous circles represent the observation range of the Poldirad radar. The observation range of the X-band radar is represented by the dashed circles on the simulation images and by a white circle on the observation images. 
and 7c), we note that the cloud system is seen at $10-15 \mathrm{~km}$ distance by the X-band radar and at $35-45 \mathrm{~km}$ by the Poldirad radar. Thus, the observations are between 880 and $1300 \mathrm{~m}$ altitude for the X-band radar but between 1200 and $1500 \mathrm{~m}$ for POLDIRAD. This explains the slightly different radar observations, especially at the beginning (see Figs. 6a and 7a).

Radar reflectivity is calculated from the simulation by taking into account the simulated hydrometeor size distribution. The sixth momentum of the raindrop size distribution is used to calculate the radar reflectivity factor $Z$ for liquid hydrometeors:

$Z\left[\mathrm{~mm}^{6} \mathrm{~m}^{-3}\right]=\int N(D) D^{6} d D$.

For the ice phase we use the approach of Delanoë et al. (2005):

$Z\left[\mathrm{~mm}^{6} \mathrm{~m}^{-3}\right]=\frac{\left|K_{i}\right|^{2}}{\left|K_{w}\right|^{2}}\left(\frac{\rho_{w}}{\rho_{i}}\right)^{2} \int N(D) D^{6} d D$

The ice and water di-electrical constants are $\left|K_{i}\right|^{2}=0.176$ and $\left|K_{w}\right|^{2}=0.93$, respectively. For the comparison with the radar observations we use herein the normalized radar reflectivity $Z_{\mathrm{dB} Z}$ :

$Z_{\mathrm{dBZ}}=10 \log \left[\frac{Z\left[\mathrm{~mm}^{6} \mathrm{~m}^{-3}\right]}{Z_{0}}\right]$

with $Z_{0}=1 \mathrm{~mm}^{6} \mathrm{~m}^{-3}$. However, the ice phase contribution is quite small in the case study of 12 August 2007.

The modelled precipitating cells are close to the observed location (Figs. 6 and 7) and intensities. For the X-band observations we note a shift of $5 \mathrm{~km}$ in the modelled reflectivity maxima. Also, the track of the modelled cells is slightly shifted to the north. Simulated radar reflectivities lower than $10 \mathrm{dBZ}$ cover a larger horizontal extension than the observed ones. This can be due to the model resolution of $250 \mathrm{~m}$ which is coarse compared with the $60 \mathrm{~m}$ radial radar resolution of the X-band radar. If we compare the simulation results with the POLDIRAD observations, we can also find a larger horizontal extension of the modelled low radar reflectivity. Likewise, the model maximum intensities are slightly weaker than those of POLDIRAD.

For a more objective method to compare the radar measurements with the model results, we analysed the probability density function (PDF) of the radar reflectivities. We selected a resolution of $1 \mathrm{dBZ}$ for the probability function and restricted the analyses of modelled and observed values to the range from 10 to $60 \mathrm{dBZ}$. The range below $10 \mathrm{dBZ}$ was excluded due to noisy data of the X-band radar. Fig. 8a shows the PDF for measurements at 13:22 UTC and model results 20 min after rain onset. We can see that the observations between the X-band radar and POLDIRAD show slight differences. For reflectivities between 20 and $35 \mathrm{dBZ}$ the Xband PDF values are higher than POLDIRAD, while in the range from 40 to $50 \mathrm{dBZ}$ the X-band reflectivity PDF values remain below the ones of POLDIRAD. The model shows a frequency distribution that is closer to the observations with POLDIRAD. In Fig. $8 \mathrm{~b}$ the mean distribution functions for the time period from 13 to $14 \mathrm{~h}$ UTC are compared. As only seven POLDIRAD scans were available, we restricted the comparison
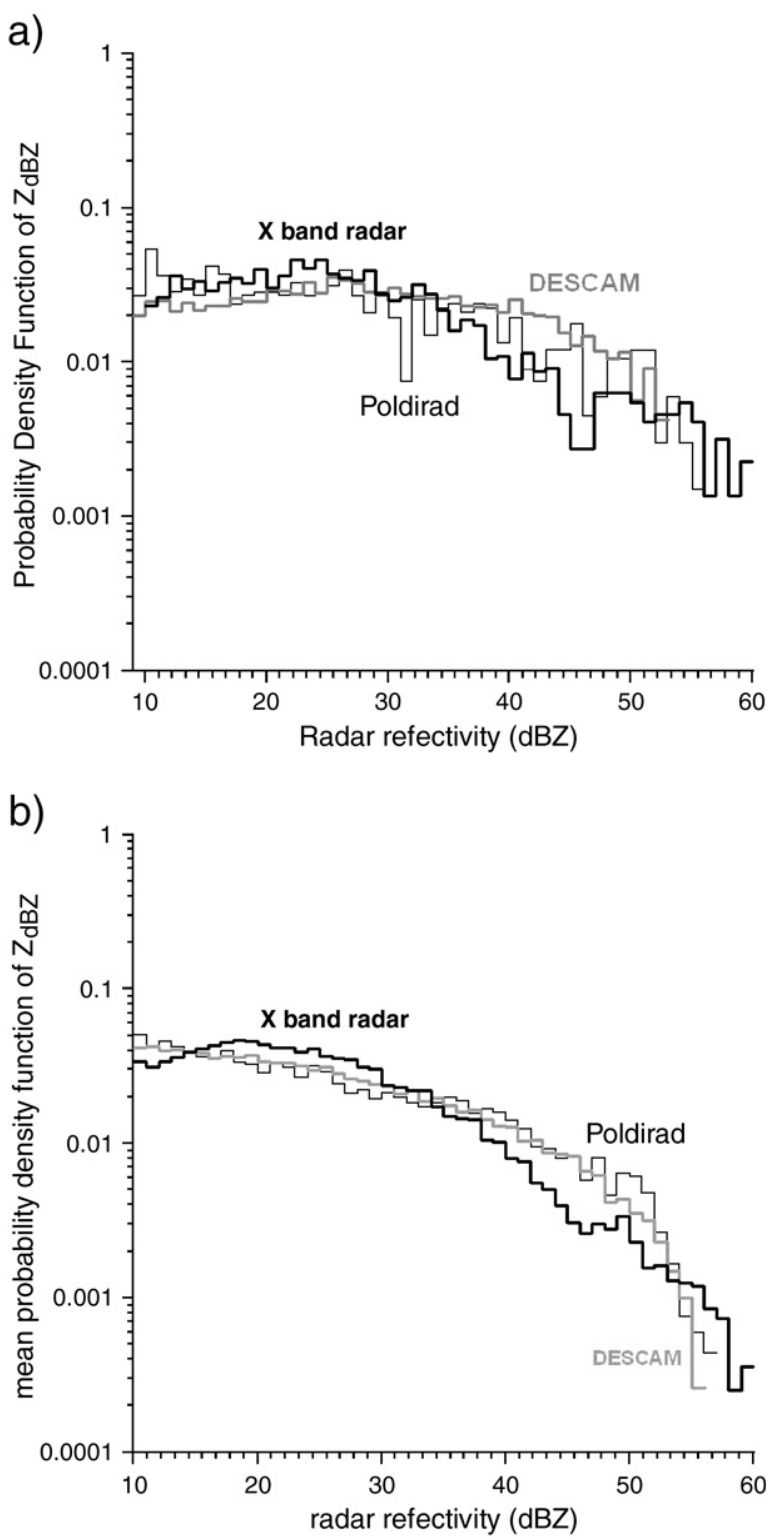

Fig. 8. Probability density function of the X-band radar with $300 \mathrm{~m}$ radial resolution (dark thick line) and Poldirad radar observations at 13:21 UTC (dark thin line) and modelled (grey thick line) with DESCAM 3D, 20 min after rain onset (a) and mean probability density functions (b) of the observations for 12 August 2007 between $13 \mathrm{~h}-14 \mathrm{~h}$ UTC and modelled during the first 35 min of precipitation.

with the X-band radar to those scans that were performed at the identical moments while the $\mathrm{X}$-band resolution was integrated over $300 \mathrm{~m}$ in order to match the POLDIRAD and model resolution. Thus, the mean PDF functions presented in Fig. $8 \mathrm{~b}$ are calculated after averaging the PDF of the radar reflectivity factor $Z$ over seven individual scans. As already revealed in Fig. 8a, the mean PDF functions confirm the good agreement between the POLDIRAD measurements and the model while differences persist especially with the X-band radar above the 40 to $50 \mathrm{dBZ}$ range of reflectivity.

Two different interpretations for these differences between POLDIRAD and the X-band radar for the radar 
reflectivities higher than $40 \mathrm{dBZ}$ are possible. The first one is that the X-band radar might present an unbalanced amplifier response in the receiver chain. That possibility is still under investigation. The second one is that the difference is real and is a consequence of the differences in the probing location and in the probing volume between both radars. This second possibility is supported by the fact that the isolated maximum in the X-band radar PDF only occurred for this convective event on the 12 August, and during the following day when convection formed east of the X-band location, i.e. in the Rhine valley, both radars show the same behaviour for the entire range of radar reflectivities. We can thus speculate that the convection which was triggered over the highly complex terrain experienced fast variations in its microphysical evolution what caused the strong changes in the observations of both radars. Also one should keep in mind that the probing volume of the X-band radar was located at about $1 \mathrm{~km}$ altitude while POLDIRAD observed at $1.35 \mathrm{~km}$.

In general, however, we can conclude that the modelled convective system on the afternoon of the 12 August 2007 reproduces satisfactorily the observed radar reflectivities.

The modelled surface rain accumulation for the entire period from $13 \mathrm{~h}$ to 14:30 is given in Fig. 9. We can detect several individual cells of intense precipitation. Their evolution is presented in Fig. 10. Unfortunately, only one rain gauge station at Le Hohwald (see also Fig. 2) is available in the discussed region. Its location is indicated in Fig. 9 by D. From $13 \mathrm{~h}$ to $14 \mathrm{~h}$ this rain gauge measured $5.2 \mathrm{~mm}$ of rain, which is in good agreement with the model result of $5.1 \mathrm{~mm}$ at the same location. From the rain evolution of the individual cells of Fig. 10, we can see that the convective event led to short but intensive rain showers over this region. A comparison with the individual radar measurements (Hagen et al., 2008 not presented here) also confirms that most of the precipitating cells developed in the beginning of this observational period as depicted by the rain showers in Fig. 10 occurring between 13:00 and 13:15 at different places. The onset and the location of the delayed shower displayed for point $\mathrm{E}$

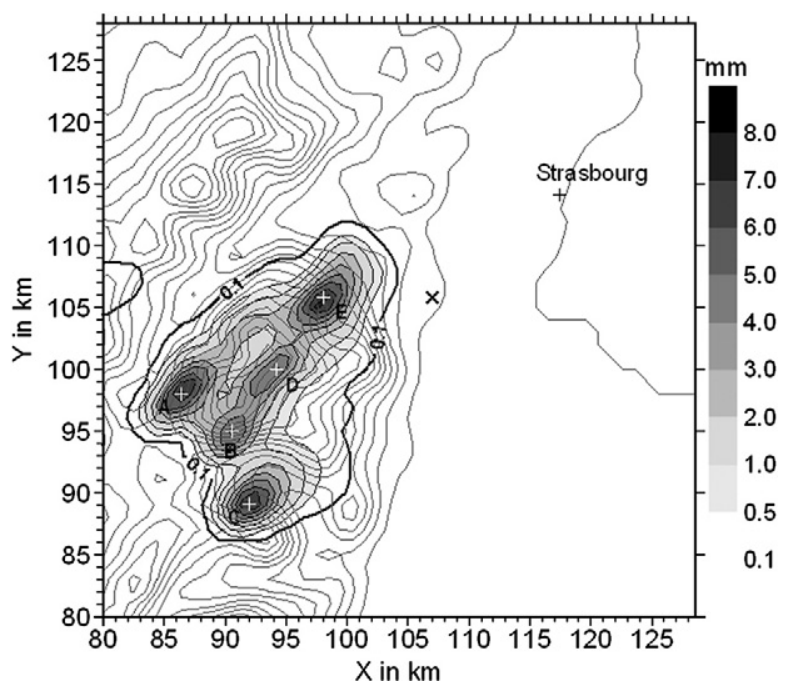

Fig. 9. Rain accumulation for the reference case after $1.5 \mathrm{~h}$ of precipitation. Point D represents the location of the rain gauge at Le Hohwald and the black cross represents the position of the X-band radar.

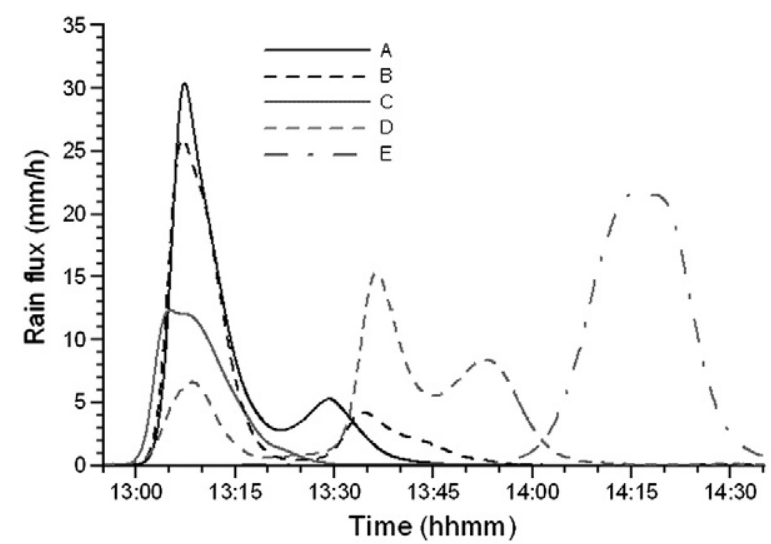

Fig. 10. Rain flux $(\mathrm{mm} / \mathrm{h})$ for the locations A, B, C, D and E of Fig. 9. Point D represents the location of the rain gauge at Le Hohwald.

(Fig. 10) $10 \mathrm{~km}$ west of the X-band radar position were also confirmed by the X-band radar observation which detected a less intensive cell of $40 \mathrm{dBZ}$ at 14:10 for this location $600 \mathrm{~m}$ above the ground. Afterwards the X-band reflectivities decreased to values lower than $25 \mathrm{dBZ}$.

As in general the features of the observed convective system were well reproduced by the model, we feel encouraged to do the planned sensitivity studies using this situation.

\section{Sensitivity studies on the influence of aerosol particle properties on cloud system evolution}

In order to study the importance of aerosol particle concentration for cloud evolution and precipitation formation, several sensitivity studies were performed varying the number of aerosol particles as well as their solubility. In contrast to the simulation presented in the previous section, model simulation for the numerous sensitivity studies following in Sections 4 and 5 restrict to the outmost model domain with a horizontal grid spacing of $1 \mathrm{~km}$. In general we noted that in all sensitivity studies the development of the spatial and temporal macroscopic cloud field stayed quite similar. This can be attributed to the relatively strong initial forcing which constrained the evolution, in order to keep the patterns comparable and allow focusing on the microphysical scale.

\subsection{Variation of the initial aerosol particle distribution}

The influence of the aerosol particle concentration has been studied by changing the number distribution of the aerosol particles for polluted and clean environments, respectively. The different aerosol particle spectra used are presented in Fig. 5 where the solid line corresponds to the reference case (Jaenicke, 1988), the dashed line corresponds to the polluted case ( 3 times the reference case) and the dot dashed line corresponds to the clean case (Raes et al., 2000). Table 1 summarizes the used coefficients for the log normal aerosol spectra. The total number of aerosol particles close to the ground is $1411 \mathrm{~cm}^{-3}$ in the reference case, $4233 \mathrm{~cm}^{-3}$ in the polluted case and $408 \mathrm{~cm}^{-3}$ in the clean case. The aerosol particles number concentration decreases exponentially up to 
Table 1

Properties of the lognormal distributions used in the clean, reference and polluted cases. The different modes $i$ of the lognormal distributions are determined by the aerosol number concentration $N_{i},\left(\mathrm{~cm}^{-3}\right)$ the geometric mean radius $R_{i}(\mu \mathrm{m})$ and the geometric standard deviation $\sigma_{i}$.

\begin{tabular}{|c|c|c|c|c|c|c|}
\hline \multirow{2}{*}{$\begin{array}{l}\text { Cases } \\
\text { Reference }\end{array}$} & \multicolumn{2}{|c|}{ Mode 1} & \multicolumn{2}{|c|}{ Mode 2} & \multicolumn{2}{|c|}{ Mode 3} \\
\hline & $N 1$ & 997 & N2 & 842 & $N 3$ & 0.00071 \\
\hline & $R 1$ & 0.001 & $R 2$ & 0.0218 & $R 3$ & 6.24 \\
\hline & $\sigma 1$ & 2.1 & $\sigma 2$ & 3.2 & $\sigma 3$ & 1.9 \\
\hline \multirow[t]{3}{*}{ Clean } & $N 1$ & 250 & N2 & 157 & N3 & 1.1 \\
\hline & $R 1$ & 0.018 & $R 2$ & 0.072 & R3 & 0.4 \\
\hline & $\sigma 1$ & 1.4 & $\sigma 2$ & 1.5 & 03 & 1.4 \\
\hline \multirow[t]{3}{*}{ Polluted } & $N 1$ & 2991 & $N 2$ & 2516 & N3 & 0.00213 \\
\hline & $R 1$ & 0.001 & $R 2$ & 0.0218 & $R 3$ & 6.24 \\
\hline & $\sigma 1$ & 2.1 & $\sigma 2$ & 3.2 & 03 & 1.9 \\
\hline
\end{tabular}

$3 \mathrm{~km}$ altitude, then it is kept constant. The chemical composition of the particles is the same as in the reference case.

Table 2 shows the results of model simulations for the different aerosol particle concentrations 30 min after precipitation onset. The spatial averages and maxima (Table 2 ) were calculated for the area presented in Fig. 9. The data for the cumulative rain amount were taken at the surface while data for the relative humidity and rain drop number were taken at $2 \mathrm{~km}$ altitude level. For the average values, we only considered in-cloud conditions with grid points whose relative humidity is higher or equal $100 \%$.

The results obtained for the reference, polluted and clean cases show that the number of drops, the rain amount and the relative humidity are quite sensitive to the number of aerosol particles. The number of drops proportionally increases with the aerosol particle concentration. The correlation of the rain amount and the relative humidity is inverse. Fig. 11 which represents the droplet mass spectra for all 3 cases after $30 \mathrm{~min}$ of precipitation in $2400 \mathrm{~m}$ above point $\mathrm{C}$, shows that the CCN concentration not only affects the concentration of the drops but also their size. The more aerosol particles are in the atmosphere the smaller the developing drops as the total quantity of condensable vapour has to be distributed over more cloud nuclei (Flossmann et al., 1985). Also the coalescence process is less efficient and droplets take a longer time to grow to precipitating sizes. Consequently, the surface precipitation and in-cloud supersaturation decrease in comparison to the reference simulation (see Table 2 for details).

The opposite is found for the clean case. As a result of higher in-cloud supersaturation, cloud droplets grow quicker to rain drop size which leads to more rain at the surface.

The Fig. 12a and $\mathrm{b}$ confirm this behaviour for the different cases. They represent the difference of cumulative rain amount at the ground between the reference case and the polluted (a) and clean (b) cases, respectively. Note that the blue colour in Fig. 12a indicates higher rain accumulation for the reference case, while the red colour in Fig. 12b indicates higher values for the clean case. These differences were calculated when precipitation terminated after a total time of $1.5 \mathrm{~h}$. The local modifications of the rain amount are also accompanied by a time delay during the development of the individual rain cells. In the first $45 \mathrm{~min}$ a delay of 3 to $5 \mathrm{~min}$ occured for the rain onset in the polluted case and it increased up to $10 \mathrm{~min}$ until the end of the precipitation phase.

The changes in aerosol number concentration cause in certain locations a modification in total rain ranging from $-3 \mathrm{~mm}$ up to $+5 \mathrm{~mm}$ (Fig. 12a and b). Thus, changes in aerosol number can locally have both effects: rain increase and rain decrease. Analysing the mean and maximum characteristics for the 3 scenarios makes the effect of the aerosol number concentration on the precipitation more visible. Table 3 shows absolute maxima of rain of $7.42 \mathrm{~mm}$ for the reference case, $6.39 \mathrm{~mm}$ for the polluted case and $8.02 \mathrm{~mm}$ for the clean case (read columns with $100 \%$ solubility). The mean rainfall accumulation reflects the same decreasing behaviour with increasing aerosol number concentration. From Table 3 we detect that the decrease in mean rain is associated with a decrease of the surface area which experienced rain fall from the convective system. This is most pronounced for the polluted case where $30 \mathrm{~km}^{2}$ of surface rain stayed dry. Varying the aerosol concentration, we can note that the most striking fact about the total water deposit (irrigation) is that it dropped by a factor 1.5 from $0.59 \mathrm{Mt}$ in the continental (or reference) case to $0.40 \mathrm{Mt}$ in the polluted case (approx. 30\%) whereas it increased to $0.69 \mathrm{Mt}$ (approx. 20\%) for the clean case.

Table 2

Rain amount $R$, number of rain drops $N$ and relative humidity $\mathrm{RH}$, represented by their average values as well as their maxima for the reference, clean and polluted cases (all 100\% soluble) 30 min after precipitation starts for a $48 \times 48 \mathrm{~km}^{2}$ area in the north-east of the domain ( $x$ and $y \geq 80 \mathrm{~km}$ ), at the surface for the cumulative rain amount and at $z=2 \mathrm{~km}$ for the others parameters. For the average of the relative humidity, only grid points with a relative humidity higher or equal $100 \%$ are considered, this corresponds to the "in-cloud supersaturation". The last two lines present the same results for the reference case by reducing the solubility to $50 \%$ and $5 \%$.

\begin{tabular}{|c|c|c|c|c|c|c|}
\hline Cases & $\begin{array}{l}\overline{\mathrm{R}} \\
(\mathrm{mm})\end{array}$ & $\begin{array}{l}R_{\max } \\
(\mathrm{mm})\end{array}$ & $\begin{array}{c}\overline{N_{\text {drops }}} \\
\left(\mathrm{cm}^{-3}\right)\end{array}$ & $\begin{array}{l}\mathrm{N}_{\text {drops,max }} \\
\left(\mathrm{cm}^{-3}\right)\end{array}$ & $\begin{array}{l}\overline{R H} \\
(\%)\end{array}$ & $\begin{array}{l}\mathrm{RH}_{\max } \\
(\%)\end{array}$ \\
\hline Reference & 0.96 & 6.15 & 24.95 & 114.40 & 100.24 & 100.54 \\
\hline Clean & 1.02 & 6.57 & 18.09 & 72.16 & 100.33 & 100.74 \\
\hline Polluted & 0.81 & 4.06 & 59.69 & 310.10 & 100.07 & 100.22 \\
\hline Ref., $50 \%$ soluble & 0.97 & 6.20 & 22.22 & 101.50 & 100.28 & 100.59 \\
\hline Ref., $5 \%$ soluble & 1.00 & 6.34 & 17.58 & 69.17 & 100.29 & 100.66 \\
\hline
\end{tabular}




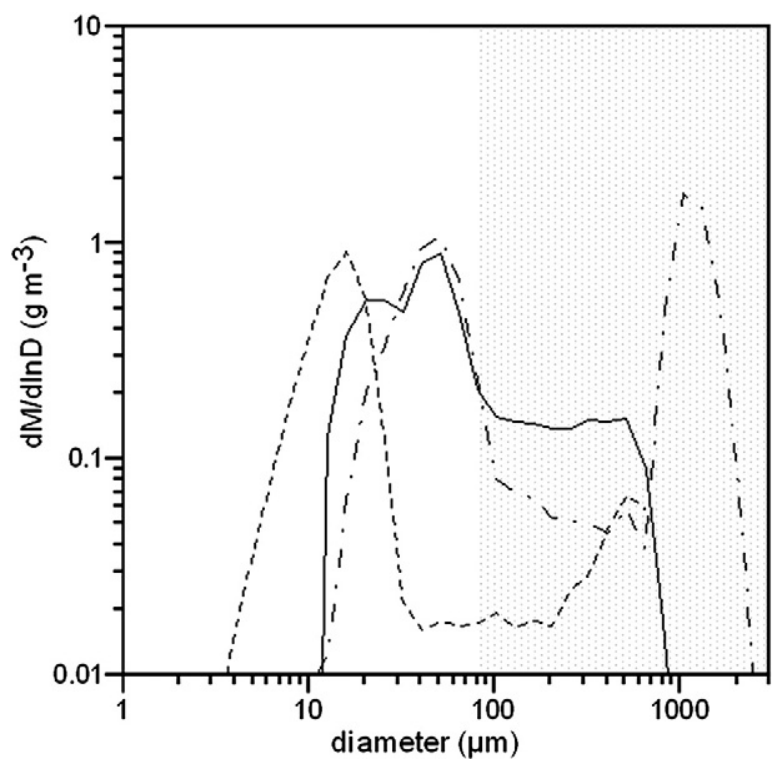

Fig. 11. Mass drop spectra for the reference (solid line), polluted (dashed line) and clean (dot dashed line) cases at $z=2400 \mathrm{~m}$ above the point $\mathrm{C}$ at 30 min after precipitation starts. The bit-mapped area corresponds to precipitating sizes.

\subsection{Impact of the hygroscopic properties of the aerosol particles}

The influence of the physico-chemical properties of the aerosol particles has been studied by reducing the solubility of the aerosol particles from $100 \%$ to $50 \%$ and to $5 \%$. For those calculations, the initial aerosol particle spectrum remains unchanged and is the same as for the reference (or continental) case (see Fig. 5). This reduction of the soluble part of the particles corresponds to a shift of the entire spectrum to smaller particle sizes.

Table 2 summarizes the results of model simulations for the different particle solubility $(50 \%, 5 \%$ in the reference case), after $30 \mathrm{~min}$ of the precipitation. The spatial averages and maxima were calculated again at the surface for the cumulative rain amount while data for relative humidity (or "in-cloud supersaturation") and droplet number were taken at $2.0 \mathrm{~km}$ altitude level. The results obtained for the different cases show that the microphysical parameters are sensitive to the solubility of the aerosol particles, however to a much lesser degree than to changes in the number concentrations of the aerosol particle spectra. Similar conclusions on the weaker sensitivities for aerosol solubility changes than for aerosol number concentration changes can be found e.g. in Reutter et al. (2009). Table 2 illustrates that the more insoluble the aerosol particles the more the rain amount and the relative humidity increase. In fact, more insoluble aerosol particle activate less and form fewer drops and produce an effect similar to a decrease in particle number (compare with the clean case in the Section 4.1). Nevertheless, the analysis of the model results for different particle solubility shows that the drop mass distributions vary only little for all 3 cases, as illustrated in Fig. 13.

The difference of cumulative rain amounts at the ground between the reference case and the case " $50 \%$ soluble" (a) as
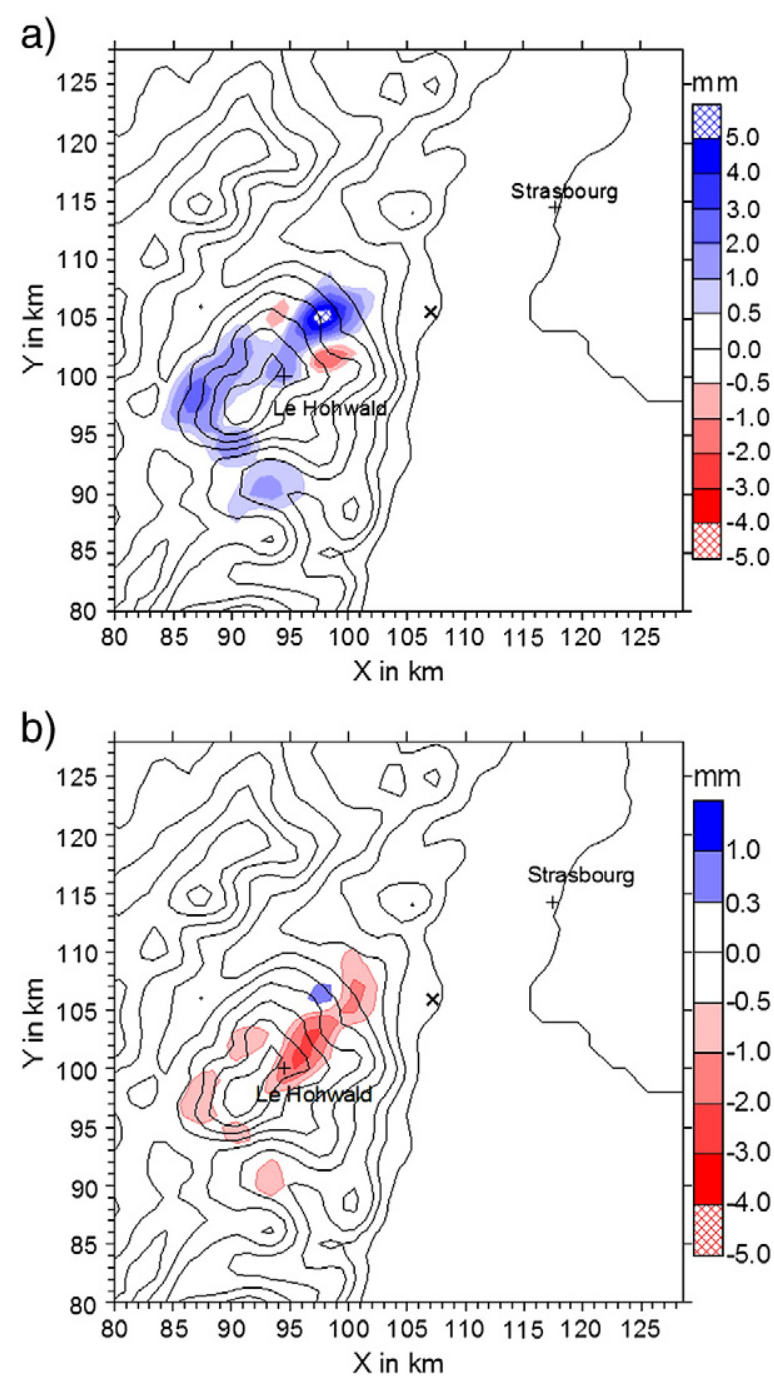

Fig. 12. Difference of rain accumulation between the reference and the polluted case (a) and between the reference and the clean case (b) in mm, $1.5 \mathrm{~h}$ after precipitation starts. The black cross represents the position of the $\mathrm{X}$-band radar. Note the change on the colour scales.

well as "5\% soluble" (b) are represented in the Fig. 14. It shows that reducing the aerosol solubility has a much smaller influence on rain intensities (note the change in the scale compared to Fig. 12). Globally, Fig. 14 depicts a weak increase in rain due to the decrease in solubility (in red), but again, also locations with reduced precipitation occur. Table 3 illustrates that the maxima of rain increase from $7.42 \mathrm{~mm}$ for the reference case (aerosol solubility equal to $100 \%$ ), to $7.52 \mathrm{~mm}$ for the $50 \%$ soluble case and $7.68 \mathrm{~mm}$ for the $5 \%$ soluble case. It also shows that the mean rain accumulation and irrigated area increase up to $10 \%$.

Moreover, Table 3 includes results of simulations for the clean and polluted aerosol cases when solubility is as well reduced to $5 \%$. A drop in aerosol solubility results again in an increase for rain accumulation and irrigated area of $10 \%$ for the clean case and $20 \%$ for the polluted case. 
Table 3

Rain maxima, mean rain and total rain area after $1.5 \mathrm{~h}$ of precipitation. The total rain area and also total precipitation (in Megatons) were calculated by counting all surface points with rain accumulations $>0.1 \mathrm{~mm}$. The percentages give the solubility of the aerosol particles imposed constant for each case study.

\begin{tabular}{|c|c|c|c|c|c|c|c|}
\hline & Reference & Reference & Reference & Clean & Clean & Polluted & Polluted \\
\hline & $100 \%$ & $50 \%$ & $5 \%$ & $100 \%$ & $5 \%$ & $100 \%$ & $5 \%$ \\
\hline Rain max. (mm) & 7.42 & 7.52 & 7.68 & 8.02 & 8.45 & 6.39 & 6.70 \\
\hline Mean rain $(\mathrm{mm})$ & 1.74 & 1.80 & 1.93 & 2.00 & 2.20 & 1.31 & 1.48 \\
\hline Rain area $\left(\mathrm{km}^{2}\right)$ & 337 & 335 & 339 & 344 & 347 & 307 & 335 \\
\hline Total rain (Mt) & 0.59 & 0.60 & 0.65 & 0.69 & 0.76 & 0.40 & 0.50 \\
\hline
\end{tabular}

\section{Statistical study about the aerosol particle influences on the "in-cloud microphysics"}

In order to study also the influence of the aerosol particles on cloud dynamics and thermodynamics we present in the following a statistical analysis of vertical wind $w$ and supersaturation $S$ which prevailed in the convective system simulated by DESCAM-3D.

As already shown in the Tables 2 and 3, supersaturation is quite sensitive to changes in the aerosol particle number concentration. As the detailed cloud modelling with DESCAM-3D explicitly treats the diffusional growth of aerosol particles and cloud droplets in combination with the three dimensional field of wind, temperature and water vapour the model results can provide fundamental insights in the behaviour of the supersaturation in the microphysics of convective clouds. In order to do so, all model grid points were analysed during the first $30 \mathrm{~min}$ of cloud and rain formation for a volume with a base of $15 \times 15 \mathrm{~km}^{2}$ and a vertical depth of $4.6 \mathrm{~km}$ which is illustrated by the square in Fig. 15. Indeed, the cloud field structure for the different scenarios is quite similar in the first 30 min of rain formation (due to the same strong surface forcing). For this study only cloudy air grid points with $S \geq 0 \%$ and total $\mathrm{LWC}>0.1 \mathrm{~g} / \mathrm{m}^{3}$

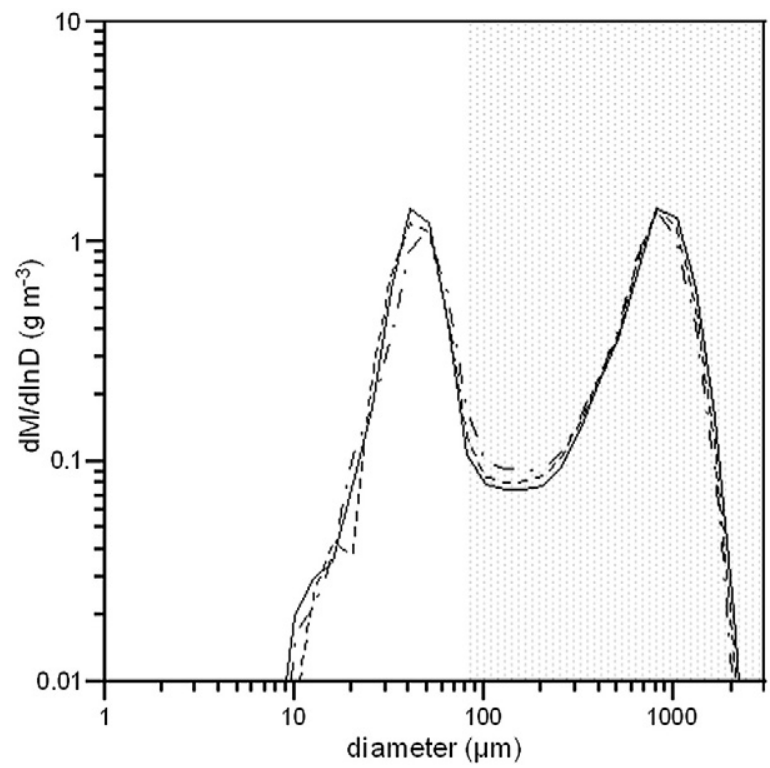

Fig. 13. Mass drop spectra for the reference (solid line), the $50 \%$ soluble (dashed line) and the $5 \%$ soluble (dot dashed line) cases at $z=2400 \mathrm{~m}$ above the point C (see Fig. 9), 30 min after precipitation starts. The bit-mapped area corresponds to precipitating sizes. (i.e. rain and cloud water) were selected to calculate the mean supersaturation as function of w. Fig. 16 shows the results for supersaturation as a function of the vertical wind speed for the different aerosol particle concentrations and different solubilities already discussed in Section 4. For the different initial aerosol distributions, each with solubilities of $100 \%$ or $5 \%$, we see that the higher the concentration of
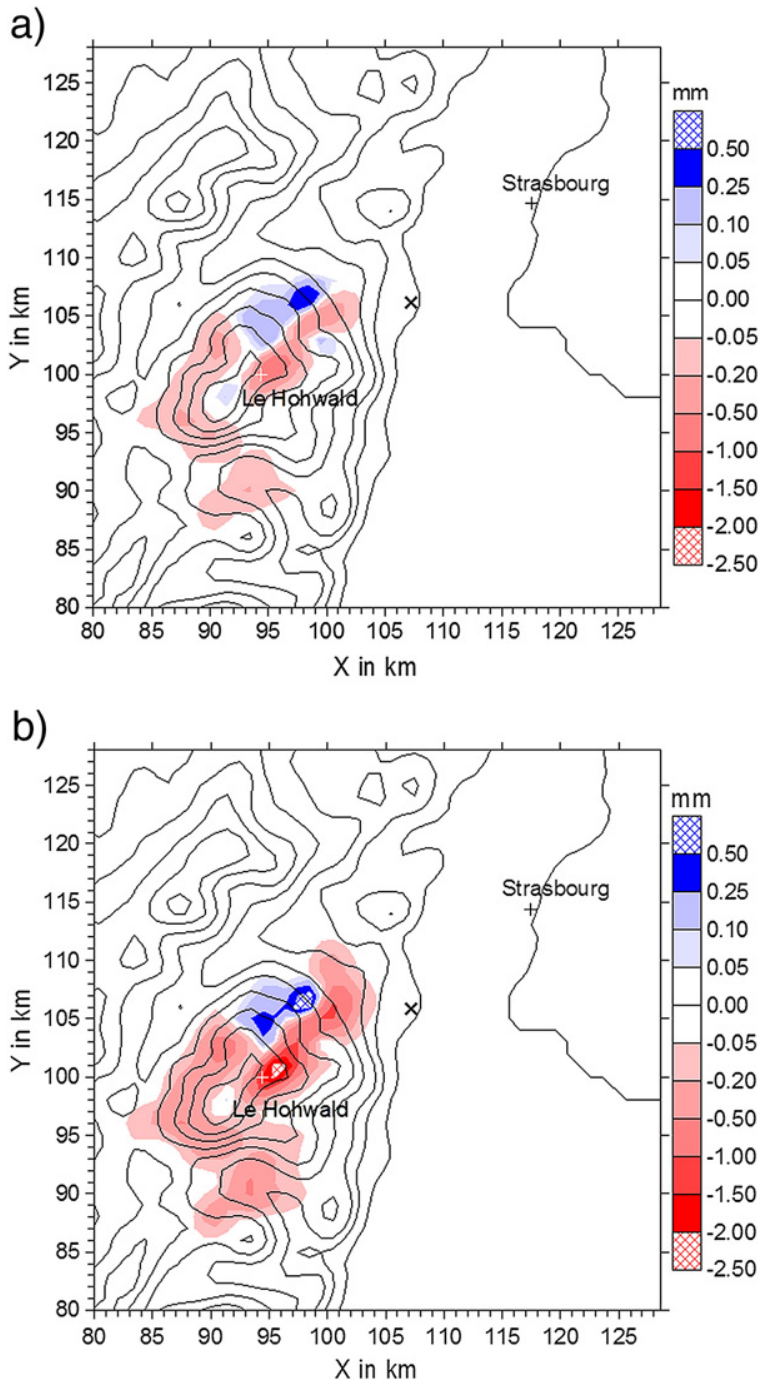

Fig. 14. Difference of rain accumulation between the reference and the $50 \%$ soluble case (a) and between the reference and the $5 \%$ soluble case (b) in $\mathrm{mm}, 1.5 \mathrm{~h}$ after precipitation starts. The black cross represents the position of the X-band radar. 


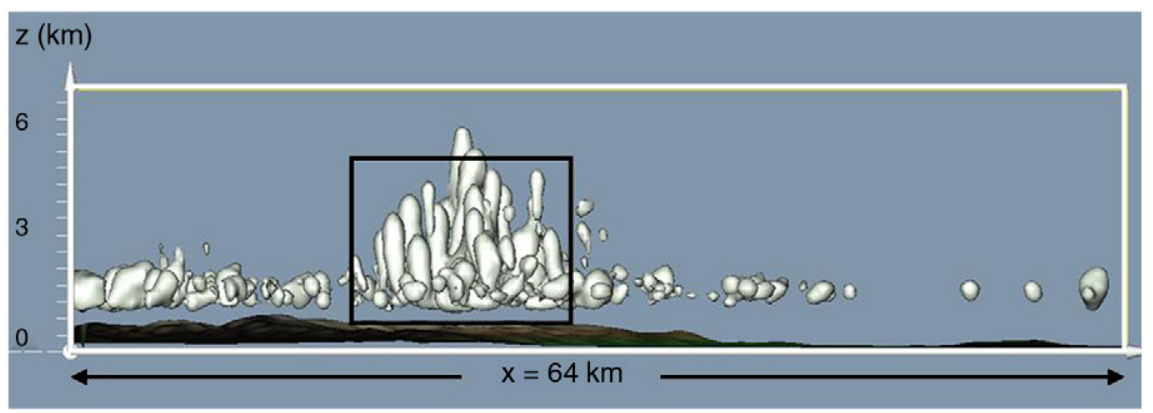

Fig. 15. Vertical cross section through the simulated convective system. The black square represents the area used for the statistical studies. The cubic volume has a base of $15 \times 15 \mathrm{~km}^{2}$ and a vertical extension of $4.6 \mathrm{~km}$. The cloud contours for LWC $\geq 0.1 \mathrm{~g} / \mathrm{m}^{3}$ is represented by the white envelope.

aerosol particles, the smaller the supersaturation. This result confirms our findings of Tables 2 and 3. In the clean cases where $\mathrm{CCN}$ are less numerous, supersaturations are the largest for the entire regime of vertical winds analysed. We can thus confirm a strong effect of the aerosol particle concentration on the cloud microphysics. The effect of the aerosol solubility, hardly visible in Table 3 and Figs. 13 and 14 becomes more apparent in Fig. 16. Comparing e.g. the result of the clean case " $100 \%$ soluble" with that of the clean case but " $5 \%$ soluble", we can notice that the mean supersaturation values increase by more than $0.1 \%$ for less soluble particles. This corresponds to a relative increase of the supersaturation condition of $20 \%$ over the entire regime of vertical wind analysed. Fig. 16 furthermore illustrates that this effect in supersaturation due to solubility changes is also present for the reference and the polluted case. For the polluted case, however, we note that the increase in $\mathrm{S}$ due to the decrease in solubility is less pronounced than for the other two cases.

Using an ensemble of 3.1 million samples which were analysed during $30 \mathrm{~min}$ of cloud evolution we found that in

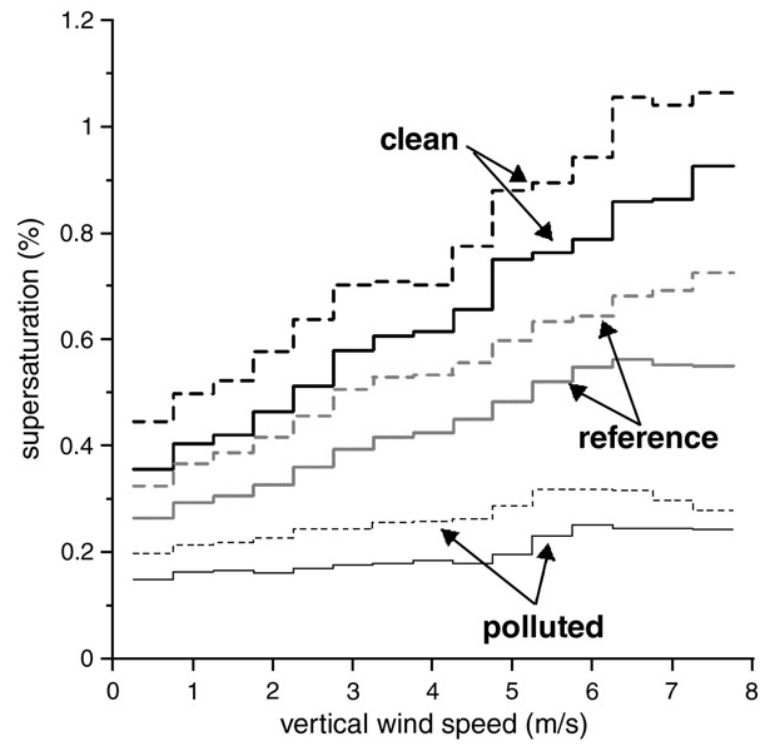

Fig. 16. Supersaturation as a function of the vertical wind speed for the reference (grey thick line), polluted (dark thin line) and clean (dark thick line) cases with the aerosol particle solubility equal to $100 \%$ (solid lines) and $5 \%$ (dashed lines). most cases a quite similar number of grid points satisfied the imposed conditions that $S \geq 0$, total LWC $>0.1 \mathrm{~g} / \mathrm{m}^{3}$ and $w \in[0.25,7.75 \mathrm{~m} / \mathrm{s}]$. Table 4 summarizes these numbers ranging between 128,000 to 142,000 grid points, which represents about $4.5 \%$ of the entire $4 \mathrm{D}$ dataset. Table 4 shows that the frequency of occurrence of cloudy and supersaturated air is highest for the lowest vertical speeds of $0.5 \mathrm{~m} / \mathrm{s}$. Grid points with high vertical winds of $7.5 \mathrm{~m} / \mathrm{s}$ are considerably less frequent. We note from Table 4 that for a given wind speed no significant changes in the number of events occurred between the individual case studies. We can, thus, notice that the number of points meeting the imposed conditions is not really affected by the initial aerosol particle concentration and solubility.

We repeated the same statistical analysis for the latent heat which was released/consumed by condensation/evaporation based on the results of the microphysical scheme in DESCAM. Again only grid points with $S \geq 0$, total $L W C>0.1 \mathrm{~g} / \mathrm{m}^{3}$ and $w \in[0.25,7.75 \mathrm{~m} / \mathrm{s}]$ were selected. Fig. 17 illustrates that for the cases studied net condensation prevails (latent heat $>0$ ) for all selected wind speeds. In addition, latent heat release increases quite linearly with the updraft strength for most of the cases. But the polluted case "100\% soluble" differs from this behaviour: a smaller increase of latent heat with increasing wind speed occurred and the heat release remains strongly below the amount found for the other cases. Combining the results of Figs. 16 and 17 we conclude that due to the high number of soluble aerosol particles in-cloud supersaturation drops notably and consequently the release of latent heat due to condensation was reduced resulting in a reduction of positive buoyancy.

In order to understand also the role of the aerosol particle number and solubility on droplet formation in the simulated convective cells the same statistical analysis was repeated for the cloud droplet number concentration. The results are illustrated in Fig. 18. We see from this analysis that (i) the average drop concentration increases when the concentration of aerosol particles increases, (ii) less droplets are formed when the aerosol is less soluble and (iii) only for vertical winds larger than $5 \mathrm{~m} / \mathrm{s}$ a clear increase of drop number becomes visible. The mean drop concentration remains for the majority of cases below or close to $80 \mathrm{~cm}^{-3}$ but increases by a factor 2 for the polluted cases.

These results are in agreement with our actual knowledge on droplet nucleation and droplet growth: a high concentration of CCN causes a higher droplet number concentration; the more soluble the aerosol particles the easier they serve as 
Table 4

Number of grid points located in cloudy air (LWC $>0.1 \mathrm{~g} / \mathrm{m}^{3}$ ). The first 6 lines refer to Figs. $16-18$, where only samples with $w>0.25 \mathrm{~m} / \mathrm{s}$ and $S \geq 0 \%$ were counted. For the last 2 lines which refer to Fig. 19 the wind condition was dropped and supersaturations were limited to $S$ [ $-1.5,1.5 \%]$.

\begin{tabular}{|c|c|c|c|c|c|c|}
\hline \multirow[t]{2}{*}{ Number of samples } & Reference & Reference & Clean & Clean & Polluted & Polluted \\
\hline & $100 \%$ & $5 \%$ & $100 \%$ & $5 \%$ & $100 \%$ & $5 \%$ \\
\hline \multicolumn{7}{|c|}{ Case study: $S \geq 0, L W C>0.1 \mathrm{~g} / \mathrm{m}^{3}$ and $w \in[0.25,7.75 \mathrm{~m} / \mathrm{s}]$} \\
\hline All grid points & 136,120 & 137,920 & 138,646 & 141,792 & 128,613 & 133,113 \\
\hline $0.5 \mathrm{~m} / \mathrm{s}$ & 39,855 & 41,455 & 41,868 & 44,274 & 41,568 & 38,723 \\
\hline $2.5 \mathrm{~m} / \mathrm{s}$ & 9807 & 10,248 & 10,124 & 9996 & 9645 & 9676 \\
\hline $5.0 \mathrm{~m} / \mathrm{s}$ & 2427 & 2228 & 2217 & 2205 & 2750 & 2620 \\
\hline $7.5 \mathrm{~m} / \mathrm{s}$ & 891 & 793 & 826 & 926 & 837 & 1037 \\
\hline \multicolumn{7}{|c|}{ Case study: $L W C>0.1 \mathrm{~g} / \mathrm{m}^{3}$ and $S \in[-1.5,1.5 \%]$} \\
\hline All grid points & 276,570 & 276,206 & 276,412 & 275,161 & 269,607 & 278,794 \\
\hline$S<0 \%$ & 51,988 & 50,158 & 49,128 & 47,128 & 62,655 & 56,225 \\
\hline
\end{tabular}

$\mathrm{CCN}$; increasing vertical winds causes an increase of cloud supersaturation and thus more droplet activation.

The small variation of $N_{\text {drop }}(w)$ for a wide range of vertical velocities in Fig. 18 remains nevertheless surprising, especially as at least $S(w)$ depicted the expected tendency in Fig. 16. Representing drop number as a function of supersaturation (not illustrated here) leads to similar results as in Fig. 18, i.e., the droplet numbers change only very little with supersaturation in the range from 0 to $1 \%$.

In order to better understand the differing behaviour of the polluted case " $100 \%$ soluble" the condition $S \geq 0$ was dropped in the analysis, thus including cloudy samples also in subsaturated air with relative humidities down to $98.5 \%$. The "cloudy" condition i.e. total LWC $>0.1 \mathrm{~g} / \mathrm{m}^{3}$ was maintained but the updraft condition $w>0 \mathrm{~m} / \mathrm{s}$ had also to be dropped. The probability density distributions for supersaturation are presented in Fig. 19. We see that in most cloudy air samples supersaturation prevails between 0 and $0.1 \%$ for the polluted case, between 0.2 and $0.3 \%$ for the continental case and

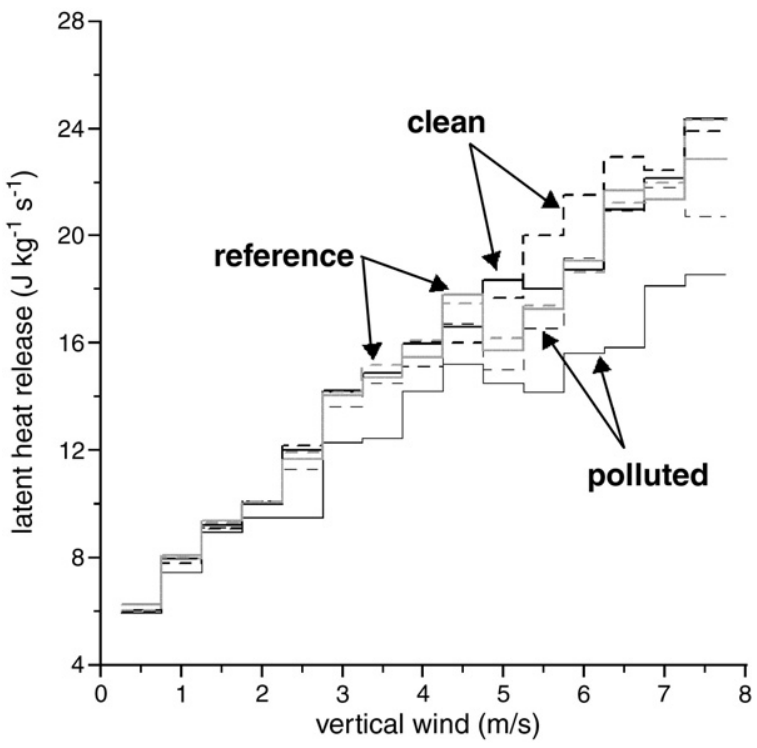

Fig. 17. Mean latent heat released in Joule per $1 \mathrm{~s}$ and per $1 \mathrm{~kg}$ of cloudy air as a function of the vertical wind speed for the reference (grey thick line), polluted (dark thin line) and clean (dark thick line) cases with the aerosol particle solubility equal to $100 \%$ (solid lines) and 5\% (dashed lines). between 0.3 and $0.4 \%$ for the clean case respectively. For the cases with $5 \%$ solubility the behaviour is similar but the maximum position for $S$ increased by $0.1 \%$ for all cases compared to $100 \%$ soluble. This illustration thus confirms our findings from Fig. 16 for supersaturated air. However, in Fig. 19 we can also detect that a significant number of subsaturated air is present in the analysed convective cloud. This is most important for the polluted case " $100 \%$ soluble".

The total amount of samples found for each of the 6 cases is also given in Table 4 in the line labelled $S<0 \%$. We can see from these values in Table 4 that the numbers among the six different cases vary only very little. Thus, from Fig. 19 and Table 4 (last line) results that the convective cloud system obviously consists in the polluted case " $100 \%$ soluble" to one quarter of subsaturated air parcels. For the other cases subsaturated cloud parcel are significantly less frequent.

We can conclude that in the presence of a high number concentration of soluble aerosol particles convective clouds contain an important number of droplets. This high number of droplets causes the cloud to prevail in a quite low level of

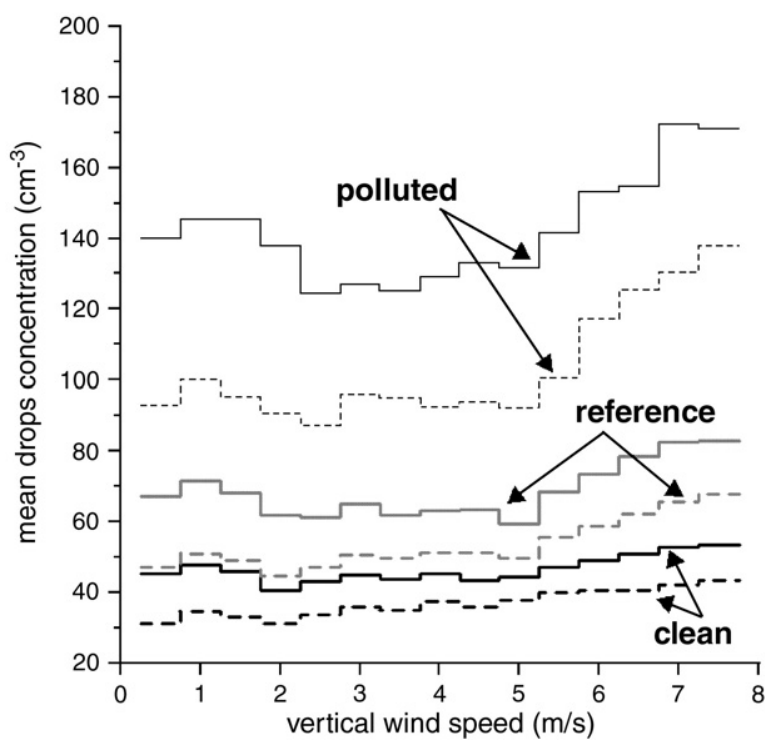

Fig. 18. Mean drop concentration as a function of the vertical wind speed for the reference (grey thick line), polluted (dark thin line) and clean (dark thick line) cases with the aerosol particle solubility equal to $100 \%$ (solid lines) and 5\% (dashed lines). 


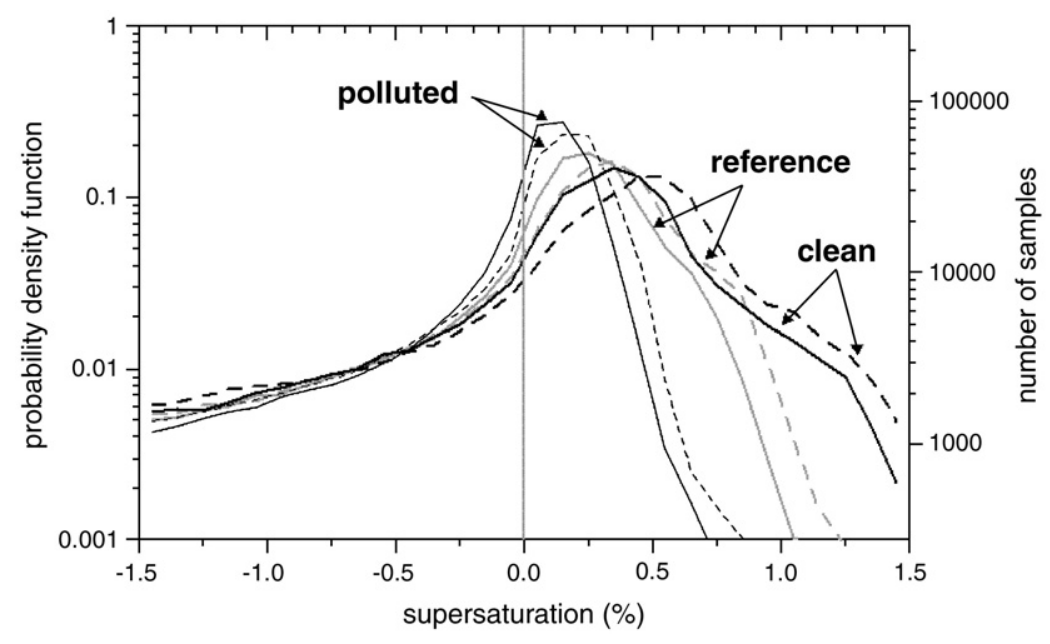

Fig. 19. Probability density function for the occurrence of cloudy air (LWC $>0.1 \mathrm{~g} / \mathrm{m}^{3}$ ) as a function of supersaturation for the reference (grey thick line), polluted (dark thin line) and clean (dark thick line) cases with the aerosol particle solubility equal to $100 \%$ (solid lines) and $5 \%$ (dashed lines). The right axis gives the number of occurences for the reference case $100 \%$ soluble.

supersaturation. Herein also subsaturated cloudy air parcels are more frequent than under less polluted aerosol conditions. Furthermore the low level of saturation affects cloud dynamics: low supersaturations limit the condensational growth of droplets, whereby less latent heat release occurs and the cloudy air becomes less buoyant as already illustrated by Fig. 17.

\section{Conclusion}

In this study for the first time a highly resolved 3D cloud model with detailed microphysics called DESCAM 3D is used to simulate a convective cloud system of medium altitude of cloud top. This cloud system was observed during the COPS campaign that took place at the French/German border during summer 2007. Measurements of the radar reflectivity and rain gauge are available. The cells were initiated over the Vosges Mountains (France) and persisted there for about $1.5 \mathrm{~h}$ irrigating a ground surface of about $340 \mathrm{~km}^{2}$. The simulated radar reflectivity fields and cumulative rain amount show a reasonable agreement with the high resolution X-band and POLDIRAD radar observations and with the rain gauge of Le Hohwald, even if the statistical behaviour of the two radars are slightly different.

We investigated the role of the initial aerosol particle concentration and solubility on the cloud evolution and precipitation formation.

Focussing first on the role of number concentration we can conclude that an increasing aerosol particle number is the principal parameter that influences precipitation formation. Particle enhancement affects in the first place the microphysical features in the convective cloud by reducing supersaturation, condensational growth, and thus the efficiency of collision-coalescence. Our model results demonstrate that the overall rain decreases due to a decrease in rain intensity as well as a reduction of the irrigated surface area. As the "incloud" microphysics and, thus, the cloud evolution were modified also the location of precipitation can change. Thus, locally the enhancement of the number concentration of aerosol particles can also cause an increase of rain. Averaging in space and time over the entire precipitation event, however, precipitation always decreased.

Decreasing the particle solubility causes an increase in precipitation: less aerosol particles activate less droplets, a higher supersaturation prevails and allows a stronger droplet growth resulting in higher efficiency for collision-coalescence. As the effect of less water-soluble aerosol counteracts an increasing number concentration, a combination of both can be positive or could cancel out, dependent on conditions.

Our analysis has demonstrated that particle number and solubility influence not only the microphysical processes but also the cloud thermodynamics and cloud dynamics. The key process for the dynamics is the release of latent heat which decreases in presence of an excessive number of droplets. Consequently, the air becomes less buoyant leading to lower vertical velocities and less frequent upward motions of air parcels.

The decline in latent heat is also a consequence of the reduced supersaturation prevailing in a polluted cloud. When aerosol particles are soluble, they take up significant amounts of water vapour already in an inactivated stage. As the particles are very numerous in the polluted case water vapour mixing ratio is reduced and relative humidity in the convective cells remains more often below $100 \%$. As a further consequence large parts of the cloud remain in a subsaturated state with important numbers of wet haze particles unable to contribute in an important manner to the formation of convective precipitation.

Overall, the amount of total surface precipitation varied only moderately for most scenarios investigated. Most drastical differences occurred between the clean case with near-insoluble aerosols and the polluted case with totally soluble aerosols (Table 3). Both scenarios, however, have a quite academic character as in clean marine atmospheres, particles stem mostly from the sea surface, preferentially soluble, while in polluted atmospheres also insoluble particles, e.g. from anthropogenic sources, can be found (Warneck, 2000; Andreae and Rosenfeld, 2008).

In conclusion, our findings on the influence of aerosol particle number and solubility on precipitation and in-cloud 
characteristics of a convective cloud system can be summarized as follows:

(1) Mean precipitation quantities notably decrease when high numbers of aerosol particles prevail. Low particle hygroscopicity can partly compensate this effect. For low particle concentrations as encountered in marine and remote environments the mean rain fall characteristics differ about $20 \%$ whereas for high particle concentrations this difference reaches up to $30 \%$. Strong reduction (probably unrealistic) in particle solubility always causes a weak increase in the mean rain quantities on the order of $10 \%$.

(2) In-cloud properties are modified significantly in all scenarios. Key parameter is the supersaturation whose magnitude influences both cloud microphysics (cloud droplet and rain drop formation) as well as cloud thermodynamics and cloud dynamics. Hereby, the magnitude of supersaturation is most sensitive to the prevailing number of aerosol particles.

In order to confirm our theoretical findings on the role of atmospheric pollution on precipitation modifications, further experimental field campaigns are needed that combine measurements of the aerosol particle concentration and composition in the lower atmosphere with dense rain gauge networks and radar measurements for surface precipitation. Furthermore, more model development is needed, in particular regarding the ice phase, in order to extend the studies to cloud fields with colder cloud tops.

\section{Acknowledgements}

The calculations for this study have been done on computer facilities of IDRIS, CNRS at Orsay and CINES in Montpellier, under the project 940180. The authors acknowledge with gratitude the hours of computer time and the support provided.

\section{Appendix A. List of symbols}

$\begin{array}{ll}\partial t & \text { time step } \\ \varepsilon & \text { mass fraction of water-soluble substance in mixed } \\ & \text { aerosol particles } \\ f_{\mathrm{AP}} & \text { number distribution function of aerosol particles } \\ f_{\mathrm{d}} & \text { number distribution function of drops } \\ f_{\mathrm{i}} & \text { number distribution function of ice crystals } \\ g_{\mathrm{AP}, \mathrm{d}} & \text { mass density distribution of aerosol particle inside } \\ & \text { drops } \\ g_{\mathrm{AP}, \mathrm{i}} & \text { mass density distribution of aerosol particle inside } \\ m & \text { ice crystal } \\ m_{\mathrm{AP}} & \text { mass of drop } \\ M_{\mathrm{W}} & \text { mass of aerosol inside drops } \\ M_{\mathrm{S}} & \text { molecular weight of water } \\ N_{\mathrm{drops}} & \text { molecular weight of aerosol material } \\ N_{\mathrm{IN}} & \text { number of drops } \\ v & \text { number of ice crystals produced by nucleation } \\ & \text { sociates in water } \\ \rho_{i} & \text { density of ice } \\ \rho_{w} & \text { density of water } \\ \rho_{N} & \text { density of dry aerosol particle nucleus }\end{array}$

$r \quad$ radius of the wet aerosol particles

$r_{N} \quad$ dry size of aerosol particles inside drops

$\Re \quad$ universal gas constant

$R \quad$ rain accumulation

$R H \quad$ relative humidity

$S \quad$ supersaturation with respect to water

$S_{\mathrm{V}, \mathrm{i}} \quad$ supersaturation with respect to ice

$\sigma_{\mathrm{w}, \mathrm{a}} \quad$ surface tension of water

$T \quad$ temperature

$w \quad$ vertical wind speed

$\Phi_{\mathrm{s}} \quad$ osmotic coefficient

\section{References}

Albrecht, B., 1989. Aerosols, cloud microphysics and fractional cloudiness. Science 245, 1227-1230.

Andreae, M.O., Rosenfeld, D., 2008. Aerosol-cloud-precipitation interactions. Part 1. The nature and sources of cloud-active aerosols. Earth-Sci. Rev. 89, $13-41$.

Bott, A., 1998. A flux method for the numerical solution of the stochastic collection equation. J. Atmos. Sci. 55, 2284-2293.

Clark, T.L., 1977. A small scale dynamic model using a terrain-following coordinate transformation. J. Comput. Phys. 24, 186-215.

Clark, T.L., 1982. Three dimensional numerical model simulations of air flow over mountainous terrain: a comparison with observations. Mon. Wea. Rev. 110, 766-791.

Clark, T.L., Farley, R.D., 1984. Severe downslope windstorm calculations in two and three spatial dimensions using anelastic interactive grid nesting: a possible mechanism for gustiness. J. Atmos. Sci. 41, 329-350.

Clark, T.L., Hall, W.D., 1991. Multi-domain simulations of the time dependent Navier-Stokes equations: benchmark error analysis of some nesting procedure. J. Comp. Phys. 92, 456-481.

Connolly, P.J., Choularton, T.W., Gallagher, M.W., Bower, K.N., Flynn, M.J., Whiteway, J.A., 2006. Cloud-resolving simulations of intense Hector thunderstorms: implication for aerosol-cloud interactions. Q. J. R. Meteorol. Soc. 132, 3079-3106.

Delanoë, J., Protat, A., Testud, J., Bouniol, B., Heymsfield, A.J., Bansemer, A., Brown, P.R.A., Forbes, M., 2005. Statistical properties of the normalized ice particle size distribution. J. Geophys. Res. 110, D10201. doi:10.1029/ 2004JD005405.

Eigenmann, R., Metzger, S., Foken, T., 2009. Generation of free convection due to changes of the local circulation system. Atmos. Chem. Phys. Discuss. 9, 11367-11411.

Flossmann, A.I., Pruppacher, H.R., 1988. A theoretical study of the wet removal of atmospheric pollutants. Part III: the uptake, redistribution, and deposition of (NH4)2SO4 particles by a convective cloud using a two-dimensional cloud dynamics model. J. Atmos. Sci. 45, 1857-1871.

Flossmann, A.I., Wobrock, W., 2010. A review of our understanding of the aerosol - cloud interaction from the perspective of a bin resolved cloud scale modelling. Atmos. Res. 97, 478-497.

Flossmann, A.I., Hall, W.D., Pruppacher, H.R., 1985. A theoretical study of the wet removal of atmospheric pollutants. Part I: the redistribution of aerosol particles captured through nucleation and impaction scavenging by growing cloud drops. J. Atmos. Sci. 42, 582-606.

Hagen, M., Van Baelen, J., Richard, E., 2008. Orographic influence on the life cycle of convection, observation during the COPS field campaign. European Conference on Radar in Meteorology and Hydrology, Helsinki.

Hall, W.D., 1980. A detailed microphysical model within a two-dimensional dynamic framework: model description and preliminary results. J. Atmos. Sci. 37, 2486-2506.

Heymsfield, A.J., Iaquinta, J., 2000. Cirrus crystal terminal velocities. J. Atmos. Sci. 57 (7), 916-938.

Jaenicke, R., 1988. Aerosol physics and chemistry. In: Fischer, G. (Ed.), Landolt-Boernstein: Zahlenwerte und Funktionen aus Naturwissenschaften und Tecknik, 4b, pp. 391-457.

Koop, T., Ng, H.P., Luo, B., Tsias, A., Peter, T., 2000. Water activity as the determinant for homogeneous ice nucleation in aqueous solutions. Nature 406, 611-615.

Lee, S.S., Donner, L.J., Phillips, V.T.J., 2008. Examination of aerosol effects on precipitation in deep convective clouds during the 1997 ARM summer experiment. Q. J. R. Meteorol. Soc. 134, 1201-1220. doi:10.1002/qj.287.

Leroy, D., 2007. Développement d'un modèle de nuage tridimensionnel à microphysique détaillée - Application à la simulation de cas de convection moyenne et profonde. $\mathrm{PhD}$ thesis, available from Laboratoire 
de Météorologie Physique, Clermont-Ferrand (France). http://wwwobs. univ-bpclermont.fr/atmos/fr/Theses/Th_Leroy.pdf.

Leroy, D., Wobrock, W., Flossmann, A.I., 2007. On the influence of the treatment of aerosol particles in different bin microphysical models: a comparison between two different schemes. Atmos. Res. 85, 269-287. doi:10.1016/j.atmosres.2007.01.003.

Leroy, D., Wobrock, W., Flossmann, A.I., 2009. The role of boundary layer aerosol particles for the development of deep convective clouds: a highresolution 3D model with detailed (bin) microphysics applied to CRYSTALFACE. Atmos. Res. 91, 62-78. doi:10.1016/j.atmosres.2008.06.001.

Levin, Z., Cotton, W.R. (Eds.), 2009. Aerosol Pollution Impact on Precipitation, A Scientific Review. Springer. 386 pp.

Meyers, M.P., Demott, P.J., Cotton, W.R., 1992. New primary ice nucleation parameterizations in an explicit cloud model. J. Appl. Meteorol. 31, 708-721.

Pruppacher, H.R., Klett, J.D., 1997. Microphysics of Clouds and Precipitation, 2nd ed. Kluwer Academic. 954 pp.

Raes, F., Bates, T., McGovern, F., Van Liedekerke, M., 2000. The 2nd aerosol characterization experiment (ACE-2): general overview and main results. Tellus 52B, 111-125.

Reutter, P., Su, H., Trentmann, J., Simmel, M., Rose, D., Gunthe, S.S., Wernli, H. Andreae, M.O., Pöschl, U., 2009. Aerosol- and updraft-limited regimes of cloud droplet formation: influence of particle number, size and hygroscopicity on the activation of cloud condensation nuclei (CCN). Atmos. Chem. Phys. 9, 7067-7080.

Schroth, A.C., Chandra, M.S., Meischner, P., 1988. A C-band coherent polarimetric radar for propagation and cloud physics research. J. Atmos. Ocean. Technol. 5, 803-822.

Solomon, S., Qin, D., Manning, M., Alley, R.B., Berntsen, T., Bindoff, N.L., Chen, Z., Chidthaisong, A., Gregory, J.M., Hegerl, G.C., Heimann, M., Hewitson, B., Hoskins, B.J., Joos, F., Jouzel, J., Kattsov, V., Lohmann, U., Matsuno, T., Molina, M., Nicholls, N., Overpeck, J., Raga, G., Ramaswamy, V., Ren, J., Rusticucci, M., Somerville, R., Stocker, T.F., Whetton, P., Wood, R.A., Wratt, D., 2007. Technical Summary. In: Solomon, S., Qin, D., Manning,
M., Chen, Z., Marquis, M., Averyt, K.B., Tignor, M., Miller, H.L. (Eds.), Climate Change 2007: The Physical Science Basis. Contribution of Working Group I to the Fourth Assessment Report of the Intergovernmental Panel on Climate Change. Cambridge University Press, Cambridge, United Kingdom and New York, NY, USA.

Teller, A., Levin, Z., 2006. The effects of aerosols on precipitation and dimensions of subtropical clouds: a sensitivity study using a numerical cloud model. Atmos. Chem. Phys. 6, 67-80.

Twomey, W., 1974. Pollution and the planetary albedo. Atmos. Environ. 8, 1251-1256.

Van Baelen, J., Pointin, Y., Wobrock, W., Flossmann, A., Peters, G., Tridon, F., Planche, C., 2009. Precipitation and microphysical studies with a low cost high resolution X-band radar: an innovative project prospective. Ad. Geosci. 20, 25-32.

Warneck, P., 2000. Chemistry of the natural atmosphere, In: Dmowska, R., Holton, J.R., Rossby, H.T. (Eds.), 2nd Edition. International Geophysics Series, Vol. 71. Academic press, INC. 997 pp.

Wulfmeyer, V., Behrendt, A., Bauer, H.S., Kottmeier, C., Corsmeier, U., Blyth, A., Craig, G., Schumann, U., Hagen, M., Crewell, S., Di Girolamo, P., Flamant, C., Miller, M., Montani, A., Mobbs, S., Richard, E., Rotach, M.W., Arpagaus, M., Russchenberg, H., Schlüssel, P., König, M., Gärtner, V., Steinacker, R., Dorninger, M., Turner, D.D., Weckwerth, T., Hense, A., Simmer, C., 2008. The convective and orographically-induced precipitation study. A research and development project of the world weather research program for improving quantitative precipitation forecasting in low-mountain regions. Bull. Amer. Meteor. Soc. 89, 1477-1486.

Yi, L., Kogan, Y., Mechem, D.B., 2008. An idealized modelling study of the effect of continental air mass aerosol parameters on marine stratocumulus. Atmos. Res. 88, 157-167.

Yin, Y., Carslaw, K.S., Feingold, G., 2005. Vertical transport and processing of aerosols in a mixed-phase convective cloud and the feedback on cloud development. Q. J. R. Meteorol. Soc. 131, 221-245. 